\title{
Effect of Molecular Weight on $\mathrm{CO}_{2}$-philicity of Poly(vinyl acetate) with Different Molecular Chain Structure
}

Dongdong Hu, Yingna Zhang, Mei Su, Lei Bao, Ling Zhao and Tao Liu*

Shanghai Key Laboratory of Multiphase Materials Chemical Engineering, East China University of Science and Technology, Shanghai 200237, P. R. China.

* Corresponding Author:

Phone: +86 21 64253470; Fax: +86 21 64253528. E-mail: liutao@ecust.edu.cn. (T. Liu). 


\section{ABSTRACT}

The low molecular weight, topological structure and end group removal are expected to enhance the $\mathrm{CO}_{2}$-philicity of poly(vinyl acetate) (PVAc), which is of great interest for expanding $\mathrm{CO}_{2}$ applications as a green solvent. This work aims at investigating the effect of molecular weight $\left(M_{\mathrm{n}}\right)$ of PVAc with different molecular chain structure on the $\mathrm{CO}_{2}$-philicity through dissolution behavior measurement and molecular modeling. Well-defined 3-armed and 4-armed R-core PVAc was synthesized by RAFT polymerization, and then the corresponding xanthate groups were removed. The $\mathrm{CO}_{2}$-philicity of multi-armed PVAc was found to be inferior to that of linear one at low $M_{\mathrm{n}}$. With increasing the $M_{\mathrm{n}}$ from 1000 to 7000 $\mathrm{g} / \mathrm{mol}$, the cloud point pressures $\left(P_{\mathrm{c}}\right)$ of multi-armed PVAc first decreased, reached a minimum at a given $M_{\mathrm{n}}$, and then increased, which was different from the variation trend of the $P_{\mathrm{c}}$ of linear PVAc versus $M_{\mathrm{n}}$. In addition, removal of the xanthate groups could effectively enhance the $\mathrm{CO}_{2}$-philicity of PVAc, especially at low $M_{\mathrm{n}}$. Moreover, the molecular dynamics (MD) simulations on the interactions in polymer/ $\mathrm{CO}_{2}$ systems indicated that the multi-armed structure had different effects on the compatibility with $\mathrm{CO}_{2}$ at different $M_{\mathrm{n}}$. At low $M_{\mathrm{n}}$, the polymer-polymer interaction was the main driving force deciding the $\mathrm{CO}_{2}$-philicity due to the significant difference in different molecular chain structures. At high $M_{\mathrm{n}}$, multi-armed structure enhanced the $\mathrm{CO}_{2}$-philicity due to the synergistic effect of moderate polymer-polymer interaction and large polymer- $\mathrm{CO}_{2}$ interaction. The appropriate molecular chain structure could be selected to enhance the $\mathrm{CO}_{2}$-philicity of PVAc at a certain $M_{\mathrm{n}}$.

KEYWORDS: Poly(vinyl acetate); $\mathrm{CO}_{2}$-philicity; Molecular chain structure; Cloud point pressure; Molecular dynamics simulations 


\section{INTRODUCTION}

With the improvement of people's environmental awareness, supercritical carbon dioxide $\left(\mathrm{scCO}_{2}\right)$ has intensively emerged as a potential alternative to the common employed conventional organic solvents for industrial applications [1,2] due to its environmentally benign, non-flammability, low price and moderate critical temperature and pressure $\left(T_{\text {crit }}=\right.$ $31.1{ }^{\circ} \mathrm{C}, P_{\text {crit }}=7.38 \mathrm{MPa}$ ) [3-6]. Unfortunately, due to its weak polarity and low dielectric constant $[11,12], \mathrm{scCO}_{2}$ is a poor solvent toward macromolecules and polar biomolecules. Only fluoropolymers [7, 8] and silicone-based polymers [9, 10] exhibit relatively good $\mathrm{CO}_{2}$-philicity. Notably, both of them have a common property of weak polymer-polymer interactions relating to low cohesive energy density $[10,13]$. Besides, the $\mathrm{CO}_{2}$-philic polymers have other features in common presenting as high entropy of mixing and strong cross-interactions with $\mathrm{CO}_{2}$, which were proposed by Beckman et al [14].

Whereas, both of fluoropolymers and silicone-based polymers are expensive and non-biodegradable, causing them unfavorable to be widely applied. Efforts have been devoted to discover or synthesize green $\mathrm{CO}_{2}$-philes with low cost $[15,16]$. In comparison to the other hydrocarbon polymers such as poly(propylene oxide) (PPO), polylactic acid (PLA) and poly(methyl acrylate) (PMA), PVAc has a relatively significant solubility in $\mathrm{CO}_{2}$. PVAc with number-average molecular weight of $3090 \mathrm{~g} / \mathrm{mol}$ can dissolve at $37.6 \mathrm{MPa}$ and $25{ }^{\circ} \mathrm{C}$ with a loading of $5 \mathrm{wt} \%$ [17]. The main difference in the $\mathrm{CO}_{2}$-philicity of these polymers is attributed to accessibility of the functional groups containing carbonyl moieties (such as electron-rich acetate groups) which will cause favorable interactions with the $\mathrm{CO}_{2}$ solvent $[17$, 
18]. The specific attractive interaction between $\mathrm{CO}_{2}$ and carbonyl groups had been confirmed by Kazarian et al using the FT-IR spectroscopy [19]. Meanwhile, the ab initio calculations also indicated that $\mathrm{C}-\mathrm{H} \cdots \mathrm{O}$ hydrogen bonds [20] and weak Lewis acid-Lewis base interactions [21] would enhance the stability of the binding between $\mathrm{CO}_{2}$ and carbonyl groups. But even so, the solubility of PVAc in $\mathrm{CO}_{2}$ was much lower than that of fluoropolymers due to the strong polymer-polymer interaction $[22,23]$.

To circumvent these intrinsic limitations, different kinds of comonomers have been chosen to synthesize PVAc-based copolymer with enhanced solubility in $\mathrm{CO}_{2}$. Howdle et al. [24] demonstrated that poly(vinyl acetate-alt-dibutyl maleate) (PVAc-alt-PDBM) copolymers showed a significant increased solubility in $\mathrm{CO}_{2}$ approaching that of perfluoropolyether (PFPE) and poly(dimethylsiloxane) monomethacrylate (PDMS-mMA). Molecular dynamics (MD) simulations by $\mathrm{Hu}$ et al. [25] also confirmed that PVAc-alt-PDBM had the relatively higher $\mathrm{CO}_{2}$-philicity because of the weaker polymer-polymer interaction in comparison to other comonomers including dimethyl maleate (DMM) and diethyl maleate (DEM). Furthermore, introduction of monomer such as vinyl butyrate [26], vinyl pivalate (VPi) [27] and 1-(trifluoromethyl) vinyl acetate [28], could also reduce the $P_{\mathrm{c}}$ in comparison with the PVAc homopolymer. The topological structure $[10,14]$ and end-group treatment $[14,29]$ are also expected to weaken the polymer-polymer interaction, resulting in increasing their solubility in $\mathrm{CO}_{2}$. Mohamed et al. [30] proposed that the existence of branched hydrocarbon tails would sufficiently reduce surface energy which was conducive to improve the $\mathrm{CO}_{2}$ compatibility. Since that, the branch effect on solubility of $\mathrm{CO}_{2}$-philes had attracted a lot of 
research attentions. Tan et al. [33] synthesized a series of PVAc with different topologies using RAFT polymerization with Z-core xanthates, where the xanthate groups served as the core of the transfer agent. Their results showed that the PVAc with more arms had higher solubility in $\mathrm{CO}_{2}$ at about $3500 \mathrm{~g} / \mathrm{mol}$. While, when continuing increasing the branching up to $1700 \mathrm{~g} / \mathrm{mol}$ its solubility would decrease, which might be attributed to the deleterious effect of the carbonate linker (used to attach the end group) on the solubility of $\mathrm{PVAc}$ in $\mathrm{CO}_{2}$ [34]. Besides, modification of the end groups with favorable functionalities could also significantly improve the polymer solubility in $\mathrm{scCO}_{2}$. Gregorowicz et al. [35] demonstrated that end-capping hyperbranched polyethers and polyester with trifluoroacetic acid anhydride or trimethylchlorosilane could enhance their $\mathrm{CO}_{2}$-philicity. Whereas, modification of the hydroxyl terminated PVAc with organic alcohols, such as phenylmethanol and hexanol, were not conducive to decrease the miscibility pressure [29]. Fedor et al. [36] also suggested that the solubility of polymer in supercritical fluids, especially at the low molecular weight, was significantly affected by the end groups. Thus, the low molecular weight, topological structure and xanthate group removal might be expected to enhance the $\mathrm{CO}_{2}$-philicity of PVAc. Nevertheless, rare studies have been comprehensively carried out to focus on the combined effect of topological structure and molecular weight on branched $\mathrm{CO}_{2}$-philes.

This work aims at investigating the effect of molecular weight of PVAc with different molecular chain structure on the $\mathrm{CO}_{2}$-philicity through dissolution behavior measurement and molecular modeling. Multi-armed R-core PVAc was first synthesized by RAFT polymerization with well-defined $M_{\mathrm{n}}$ distributions, and then the corresponding end groups 
were removed. The cloud point measurements of the samples were performed by using variable volume view cell. To obtain a deeper understanding on the interactions of polymer/ $\mathrm{CO}_{2}$ systems, MD simulations were introduced to access the effect of molecular weight and chain structure on the interaction energy, cohesive energy density (CED), and Flory-Huggins interaction parameter between $\mathrm{CO}_{2}$ and different PVAc chain. In addition, the surface tensions were also measured to verify the variation trend of polymer-polymer interaction. Furthermore, the radial distribution functions (RDF) for polymer/CO systems was applied to analyze the inter-molecular interactions at the molecular level. On the basis of the experimental and molecular modeling results, the effect of molecular weight on $\mathrm{CO}_{2}$-philicity of PVAc with different molecular chain structure was explored.

\section{EXPERIMENTAL SECTION}

\subsection{Materials}

Vinyl acetate (VAc, 99.0\%, Aladdin) was purified to remove the inhibitor by washing with saturated sodium bisulfite three times, distilled water once, and sodium carbonate aqueous solution $(10 \mathrm{wt} \%)$ twice, respectively. Thereafter, it was washed to neutral and dried by magnesium sulfate anhydrous. 2',2'-Azobis (isobutyronitrile) (AIBN, 97\%, Aladdin) was recrystallized twice from ethanol and vacuum-dried before used, and lauroyl peroxide (LPO, $98 \%$, Aladdin) was also recrystallized from toluene. Other reagents were all purchased from Aladdin Chemical Co., Ltd., and used without further purification.

\subsection{Synthesis of Multifunctional Xanthate Agent}


R-core 3-armed xanthate agent (RAFT-3). A solution of 1,1,1-Tris(hydroxymethyl) ethane $(2.40 \mathrm{~g}, 0.02 \mathrm{~mol})$, pyridine $(5.0 \mathrm{~mL})$ and anhydrous chloroform $(30.0 \mathrm{~mL})$ was added into a $100 \mathrm{~mL}$ round-bottom flask. The flask was then placed in an ice-water bath. After adding 2-bromopropionyl bromide (14.86 g, $0.07 \mathrm{~mol})$ dropwise within $30 \mathrm{~min}$, the bath was removed and the solution was kept magnetic stirring at room temperature for 60 hours. Diluted hydrochloric acid $(50 \mathrm{~mL}, 10 \mathrm{v} \%)$ was then added into the solution. The organic phase was washed using aqueous sodium hydrogen carbonate $(100 \mathrm{~mL}, 5 \mathrm{wt} \%)$ and dried with magnesium sulfate anhydrous. After the solvent was distilled under reduced pressure, the bromide intermediate product was obtained. Thereafter, a solution of the bromide intermediate product $(6.48 \mathrm{~g}, 0.01 \mathrm{~mol})$, potassium ethyl xanthogenate $(8.0 \mathrm{~g}, 0.05 \mathrm{~mol})$ and chloroform $(100 \mathrm{~mL})$ was added into a $250 \mathrm{~mL}$ flask and kept magnetic stirring for 3 days. The excessive potassium ethyl xanthogenate was then filtrated and washed several times with chloroform. The final RAFT-3 was obtained after distillation. ${ }^{1} \mathrm{HNMR}\left(\mathrm{CDCl}_{3}\right): 0.97$ (t, $\left.3 \mathrm{H}, \mathrm{C}_{3}-\mathrm{C}\right), 1.35$ (m, 9H, $\left.\underline{\mathrm{H}}_{3}-\mathrm{CH}_{2}-\mathrm{O}\right), 1.52$ (b, 9H, $\left.\underline{\mathrm{C}}_{3}-\mathrm{CH}-\mathrm{S}\right), 3.98$ (q, 6H, C-C $\left.\underline{\mathrm{H}}_{2}-\mathrm{O}\right), 4.34$ (r, 3H, CH-S), 4.57 (s, $\left.6 \mathrm{H}, \mathrm{CH}_{3}-\underline{\mathrm{CH}}_{2}-\mathrm{O}\right) .{ }^{13} \mathrm{CNMR}\left(\mathrm{CDCl}_{3}\right): 14.30\left(\underline{\mathrm{CH}}_{3}-\mathrm{CH}_{2}-\mathrm{O}\right), 17.49\left(\underline{\mathrm{CH}}_{3}-\mathrm{CH}-\mathrm{S}\right), 39.48$

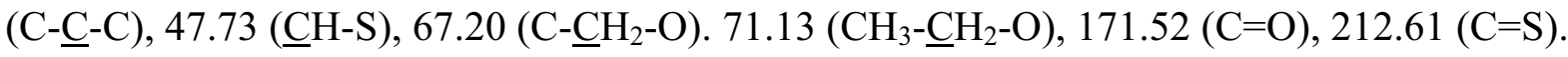

R-core 4-armed xanthate agent (RAFT-4). The synthetic method of RAFT-4 was similar to that of RAFT-3 and the biggest difference was the raw materials (as shown in Scheme 1). The bromide intermediate of RAFT-4 was synthesized with pentaerythritol and 2-bromopropionyl bromide as raw materials. A solution of pentaerythritol $(2.70 \mathrm{~g}, 0.02 \mathrm{~mol})$, pyridine $(5.0 \mathrm{~mL})$ and anhydrous chloroform $(30.0 \mathrm{~mL})$ was added into a $100 \mathrm{~mL}$ 
round-bottom flask and then placed into an ice-water bath. After adding 2-bromopropionyl bromide (19.10 g, $0.09 \mathrm{~mol})$ dropwise within $30 \mathrm{~min}$, the bath was removed and the solution was kept magnetic stirring at room temperature for 60 hours. The after-processing was same as that of RAFT-3. Thereafter, a solution of the bromide intermediate product $(8.40 \mathrm{~g}, 0.01$ mol), potassium ethyl xanthogenate $(10.1 \mathrm{~g}, 0.60 \mathrm{~mol})$ and chloroform $(100 \mathrm{~mL})$ was added into a $250 \mathrm{~mL}$ flask and kept magnetic stirring for 3 days. The final product (RAFT-4) was obtained after removing the solvent. ${ }^{1} \mathrm{HNMR}\left(\mathrm{CDCl}_{3}\right)$ : $1.42\left(\mathrm{t}, 12 \mathrm{H}, \mathrm{C}_{3}-\mathrm{CH}_{2}-\mathrm{O}\right), 1.58$ (m, 12H, $\underline{\mathrm{H}}_{3}-\mathrm{CH}-\mathrm{S}$ ), 4.14 (b, 8H, C- $\underline{\mathrm{C}}_{2}-\mathrm{O}$ ), 4.41 (q, $\left.4 \mathrm{H}, \mathrm{CH}-\mathrm{S}\right), 4.63$ (r, 8H, $\mathrm{CH}_{3}-\mathrm{CH}_{2}-\mathrm{O}$ ).

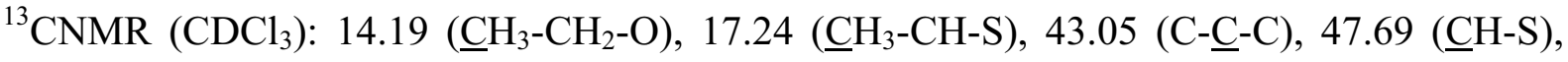
$63.50\left(\mathrm{C}-\underline{\mathrm{CH}}_{2}-\mathrm{O}\right) .71 .30\left(\mathrm{CH}_{3}-\underline{\mathrm{CH}}_{2}-\mathrm{O}\right), 171.45(\mathrm{C}=\mathrm{O}), 212.49(\mathrm{C}=\mathrm{S})$.

\subsection{RAFT Solution Polymerization of Multi-armed PVAc}

A solution of AIBN (0.36 g, $2.22 \mathrm{mmol}), 3$-armed R-core star xanthate agent $(2.87 \mathrm{~g}$, $4.44 \mathrm{mmol})$, VAc $(9.46 \mathrm{~g}, 0.11 \mathrm{~mol})$ and THF $(6.0 \mathrm{~mL})$ was added into a $100 \mathrm{~mL}$ round-bottom flask, which was connected to the condenser-west tube and sealed. The solution was degassed using several argon-vacuum cycles, and then placed in a constant temperature water-bath at $60{ }^{\circ} \mathrm{C}$ with magnetic stirring for several hours. The reaction products were dissolved into THF and then precipitated in cold hexane. After vacuum drying at $35{ }^{\circ} \mathrm{C}$ for 48 $\mathrm{h}$, the products were obtained and measured by GPC and NMR. The 4-armed R-core PVAc was also synthesized following the same procedure. 


\subsection{Removal of Xanthate Groups from multi-armed PVAc}

A solution of PVAc $\left(3.87 \mathrm{~g}, M_{\mathrm{n}, \mathrm{GPC}}=8417 \mathrm{~g} / \mathrm{mol}, 0.46 \mathrm{mmol}\right), 2$-propanol $(8 \mathrm{~mL}), \mathrm{LPO}$ $(0.6 \mathrm{~g}, 1.5 \mathrm{mmol})$ and THF $(8 \mathrm{~mL})$ was first prepared in a $100 \mathrm{~mL}$ round bottom flask and sealed. The solution was degassed using several argon-vacuum cycles, then placed into oil-bath with $80{ }^{\circ} \mathrm{C}$ constant temperature and kept magnetic stirring for 6 hours. The samples were dissolved into THF, and precipitated in cold hexane. The final products were obtained after vacuum drying for $48 \mathrm{~h}$ at $35{ }^{\circ} \mathrm{C}$ and characterized by GPC and NMR.

\subsection{Characterization}

Nuclear magnetic resonance (NMR) spectra were recorded on a Bruker AV spectrometer (400 MHz) with $\mathrm{CDCl}_{3}$ as the solvent at ambient temperature, where tetramethylsilane (TMS) was used as an internal reference. Gel permeation chromatography (GPC, Agilent 1100) was performed using refractive index detector (RID) and a chromatography column (PL gel $5 \mu \mathrm{m}$ ). THF was used as an eluent at a flow rate of $1.0 \mathrm{~mL} / \mathrm{min}$ with monodispersed polystyrene as a calibration standard.

The water contact angle measurements were examined by using a sessile drop tensiometer (Datephysics, model OCA20, Germany) at room temperature. An accurate amount of polymer was dissolved in 2-butanone and filtered through a $0.45 \mu \mathrm{m}$ Nylon filter to obtained a polymer solution of $10 \mathrm{wt} \%$. Then, the dried homogeneous polymer film was prepared by spin-coating on a clean glass slide at a constant spinning rate of $1500 \mathrm{rpm}$ for 60

s. The water drop $(2 \mu \mathrm{L})$ was deposited on the surface of the coated slide and analyzed by 
drop shape analysis software. Each measurement was repeated for five times and averaged.

\subsection{Solubility measurements in $\mathrm{scCO}_{2}$}

A high-pressure variable volume view cell (from 25.0 to $50.0 \mathrm{~mL}$ ) which had been described previously [25] was used to measure the $P_{\mathrm{c}}$ of the polymers in $\mathrm{scCO}_{2}$. In a typical experiment, an accurate amount of polymer $\left(0.2 \mathrm{wt} \%\right.$ based on the weight of injected $\left.\mathrm{CO}_{2}\right)$ was placed at the bottom platform of the cell. The sealed cell was heated to $35^{\circ} \mathrm{C}$ with a slow flow of $\mathrm{CO}_{2}$ to remove the air in 5 minutes. Then, the pressure of the system increased by injecting pure $\mathrm{CO}_{2}$ with a booster pump. With increasing pressure and stirring, the polymer completely dissolved in $\mathrm{CO}_{2}$. After the system stabilized, the cell volume was enlarged slowly to reduce the pressure. The single transparent homogeneous phase would become cloudy at a certain pressure, that was, the cloud point pressure $\left(P_{\mathrm{c}}\right)$. All the $P_{\mathrm{c}}$ of the samples in $\mathrm{CO}_{2}$ were repeated 3 times and the deviation of the $P_{\mathrm{c}}$ was usually no more than $\pm 0.1 \mathrm{MPa}$.

\section{COMPUTATION SECTION}

In the dissolution process of polymer in $\mathrm{CO}_{2}$, polymer- $\mathrm{CO}_{2}$ interaction and polymer-polymer interaction are the important parameters for screening suitable $\mathrm{CO}_{2}$-philic polymers. They should be considered simultaneously to predict the compatibility between polymer and $\mathrm{CO}_{2}$. $\mathrm{MD}$ simulations were implemented to evaluate the inter-molecular interaction and cohesive energy density (CED) in the polymer $/ \mathrm{CO}_{2}$ systems by using Material Studio software package in this work. The condensed-phase optimized molecular potential for atomistic simulation studies force field (COMPASS) [37] was applied to describe the 
potential energy functions of all atoms in the simulations. COMPASS, an all-atom force field on the basis of the $a b$ initio calculations and the optimization with experimental data, has been validated to be capable of predicting the structural and thermo-physical properties of hydrocarbon polymers $[37,38]$ and $\mathrm{CO}_{2}[39]$. The force field parameters of COMPASS used in this study had been listed in our previous work [25, 37-42] according to Sun et al. work [37-42].

The PVAc chains with different repeat units were constructed corresponding to different $M_{\mathrm{n}}$ from 2580 to $6450 \mathrm{~g} / \mathrm{mol}$. Meanwhile, the PVAc chains with 3-armed and 4-armed structure were built by using substantially the same molecular weight of the PVAc chains (Each arm had approximately the same number of repeating units in a multi-armed PVAc). Three kinds of simulation boxes were built with periodic boundary condition in Amorphous Cell approach, namely, the pure polymer system (linear, 3-armed and 4-armed structure with different $M_{\mathrm{n}}$, and the number of repeat units are about the same in each box), the polymer/ $/ \mathrm{CO}_{2}$ system introducing $1000 \mathrm{CO}_{2}$ molecules based on the pure polymer system, and the polymer/ $/ \mathrm{CO}_{2}$ system containing $1000 \mathrm{CO}_{2}$ molecules and one polymer chain. The simulation boxes with different compositions of PVAc and $\mathrm{CO}_{2}$ are gathered in Table 1 . The subscript of PVAc 30 refers to PVAc with 30 repeat units, and the abbreviation of $\mathrm{PVAc}_{30-3}$ represents the PVAc with 3-armed structure and a total of 30 repeat units. Wherein, the simulation cases involving linear PVAc ${ }_{50}$ had been simulated in our previous work [43].

The optimized calculation box was annealed from 300 to $500 \mathrm{~K}$ for five circles after the 
minimization of energy. Then the calculation was performed in the $N V T$ ensemble for $100 \mathrm{ps}$ with the time step of $1 \mathrm{fs}$ at $35^{\circ} \mathrm{C}$, and subsequent $N P T$ ensemble for 300 ps at $35^{\circ} \mathrm{C}, 20 \mathrm{MPa}$. In all the calculations, the system temperatures and the pressures of NPT ensemble were kept by using the Andersen method. The vdW interactions were evaluated by using the atom-based summation while the electrostatic interactions were calculated by using the Ewald summation. The configurations of final 50 ps were collected to analyze the thermodynamic parameters containing CED and system energy. The detailed calculation procedures can be found in our previous work [25].

Table 1. Systems with different compositions of PVAc and $\mathrm{CO}_{2}$ in $\mathrm{MD}$ simulations

\begin{tabular}{cccccc}
\hline System & Composition & $\begin{array}{c}M_{\mathrm{n}} \text { of } \\
\text { a chain }\end{array}$ & $\begin{array}{c}\text { Number } \\
\text { of chains }\end{array}$ & $\begin{array}{c}\text { Number of } \\
\text { units in a chain }\end{array}$ & $\begin{array}{c}\text { Number } \\
\text { of } \mathrm{CO}_{2}\end{array}$ \\
\hline 1 & PVAc $_{30}$ & 2582 & 10 & 30 & - \\
2 & PVAc $_{38}$ & 3270 & 8 & 38 & - \\
3 & PVAc $_{50}$ & 4302 & 6 & 50 & - \\
4 & PVAc $_{60}$ & 5162 & 5 & 60 & - \\
5 & PVAc $_{75}$ & 6452 & 4 & 75 & - \\
\hline 6 & PVAc $_{30}-\mathrm{CO}_{2}$ & 2582 & 1 & 30 & 1000 \\
7 & PVAc $_{38}-\mathrm{CO}_{2}$ & 3270 & 1 & 38 & 1000 \\
8 & PVAc $_{50}-\mathrm{CO}_{2}$ & 4302 & 1 & 50 & 1000 \\
9 & PVAc $_{60}-\mathrm{CO}_{2}$ & 5162 & 1 & 60 & 1000 \\
10 & PVAc $_{75}-\mathrm{CO}_{2}$ & 6452 & 1 & 75 & 1000 \\
\hline 11 & PVAc $_{30}-\mathrm{CO}_{2}$ & 2582 & 10 & 30 & 1000 \\
12 & PVAc $_{38}-\mathrm{CO}_{2}$ & 3270 & 8 & 38 & 1000 \\
13 & PVAc $_{50}-\mathrm{CO}_{2}$ & 4302 & 6 & 50 & 1000 \\
14 & PVAc $_{60}-\mathrm{CO}_{2}$ & 5162 & 5 & 60 & 1000 \\
15 & PVAc $_{75}-\mathrm{CO}_{2}$ & 6452 & 4 & 75 & 1000 \\
\hline
\end{tabular}




\section{RESULTS AND DISCUSSION}

\subsection{Controlled/living Solution Polymerization of R-core Multi-armed PVAc with R-core}

Multifunctional Xanthate Agents

By using the core-first strategy of the RAFT polymerization with the Z-core star xanthate agent, it is unable to remove the thiocarbonylthio groups of star PVAc because they serve as the linkage in the core while the star polymer arms grow [33, 44]. While another xanthate agent (the R-core xanthate agent) has a special structure that the reactive RAFT groups (the thiocarbonylthio groups) are in the end of the star structure. Thus, the thiocarbonylthio groups remain in the end while the star arms grow, providing convenience to remove the xanthate end group. In addition, the molecular weight as well as molecular structure can be well controlled by the R-core multifunctional star xanthate agent [45].

In this work, the 3-armed and 4-armed R-core star xanthate agent were synthesized as shown in Scheme 1 and then used as the chain transfer agent for the RAFT polymerization of the muti-armed PVAc, which was performed at $60{ }^{\circ} \mathrm{C}$ with $\mathrm{AIBN}$ as the initiator and THF as the solvent. In the case of ${ }^{1} \mathrm{HNMR}$ analysis for 4-armed PVAc, the chemical shift of the $\mathrm{H}$ atom belonging to RAFT-4 in b, e, a (as shown in the Figure 1a) are observed at 4.63 ppm, $4.14 \mathrm{ppm}, 1.42 \mathrm{ppm}$, respectively. The area integration ratio of these peaks agrees well with the theoretical value $(2: 2: 3)$. Figure $1 \mathrm{~b}$ is the ${ }^{1} \mathrm{HNMR}$ spectrum of 4 -armed PVAc polymerized by RAFT-4. The chemical shift of $b$, e, a remain the same, while the proton of $i$ shifts from 4.41 to 2.21. The methane, methylene and methyl protons in the main chain of the 4-armed 
PVAc with the thiocarbonylthio end groups show broad complex peaks (d, c and $\mathrm{f}$ ) at 4.75-5.10 ppm, 1.55-1.95 ppm and 1.95-2.20 ppm, respectively, resulting from stereoisomers. The area ratio of the peaks $\mathrm{d}, \mathrm{c}$ and $\mathrm{f}$ is $43: 100: 140$, which is approximately $1: 2: 3$ and consistent with the expected value. These results demonstrats that the 4-armed R-core star PVAc has been successfully synthesized. The ${ }^{1} \mathrm{HNMR}$ analysis for 3-armed PVAc was shown in Figure S1 of the Supporting Information.

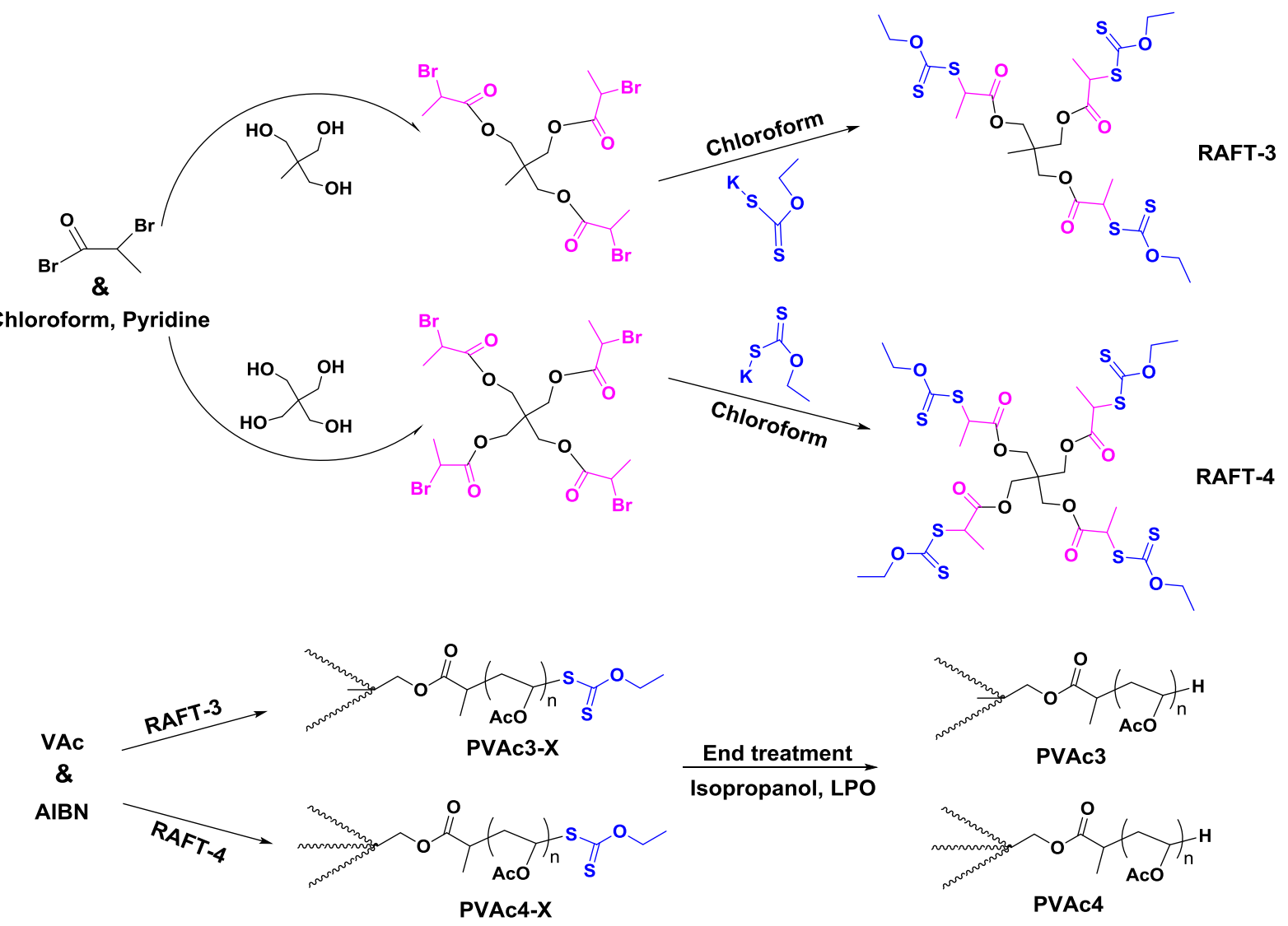

Scheme 1. Synthesis route of muti-armed PVAc with end treatment. 


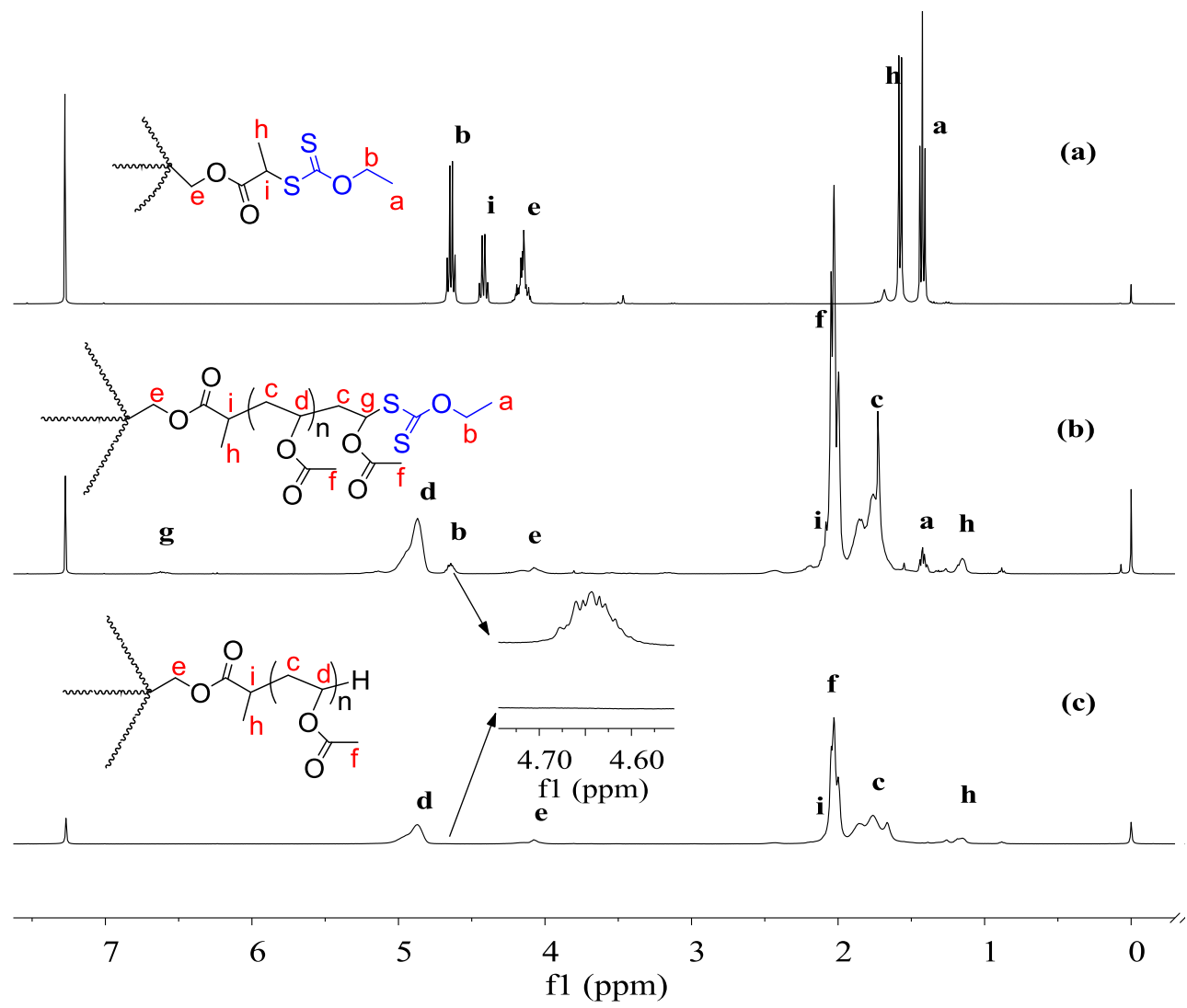

Figure 1. ${ }^{1} \mathrm{HNMR}$ spectra of (a) 4-armed R-core star xanthate agent and corresponding (b) 4-armed R-core star PVAc and (c) the end-removed product.

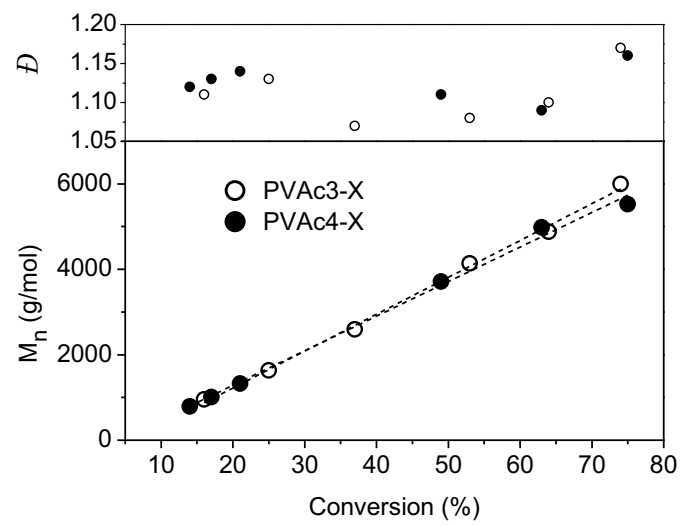

Figure 2. Evolution of the molecular weight and dispersity of molecular weight distribution with conversion for polymerization with two 3-armed and 4-armed RAFT agents of VAc at $60{ }^{\circ} \mathrm{C}$. The lines only indicate the trend.

Figure 2 shows the dependences of the $M_{\mathrm{n}}$ and the dispersity of molecular weight distribution $(Ð)$ on the conversion for the polymerization of the star PVAc with 3-armed and 4-armed R-core star xanthate agents, respectively. Both of these two systems had a narrow 
molecular weight distribution (as illustrated in Figure S2 in the Supporting Information). The approximately linear dependence of the molecular weight on the conversion reveals that the conversion increases with increasing molecular weight, confirming that the RAFT solution polymerizations of PVAc performes in the presence of the 3-armed and 4-armed R-core star xanthate agents are generally completed with good controlled/living. As a result, the target R-core star PVAc with the low molecular weight and narrow molecular weight distribution could be well controlled by transforming the ratio of VAc monomer and chain transfer agent or changing the reaction time. Convinced by these results, plenty of multi-branched polymers with different target molecular weight and narrow molecular weight distribution were successfully synthesized as shown in Table 2. The GPC traces for the samples are exhibited in Figure S3 of the Supporting Information.
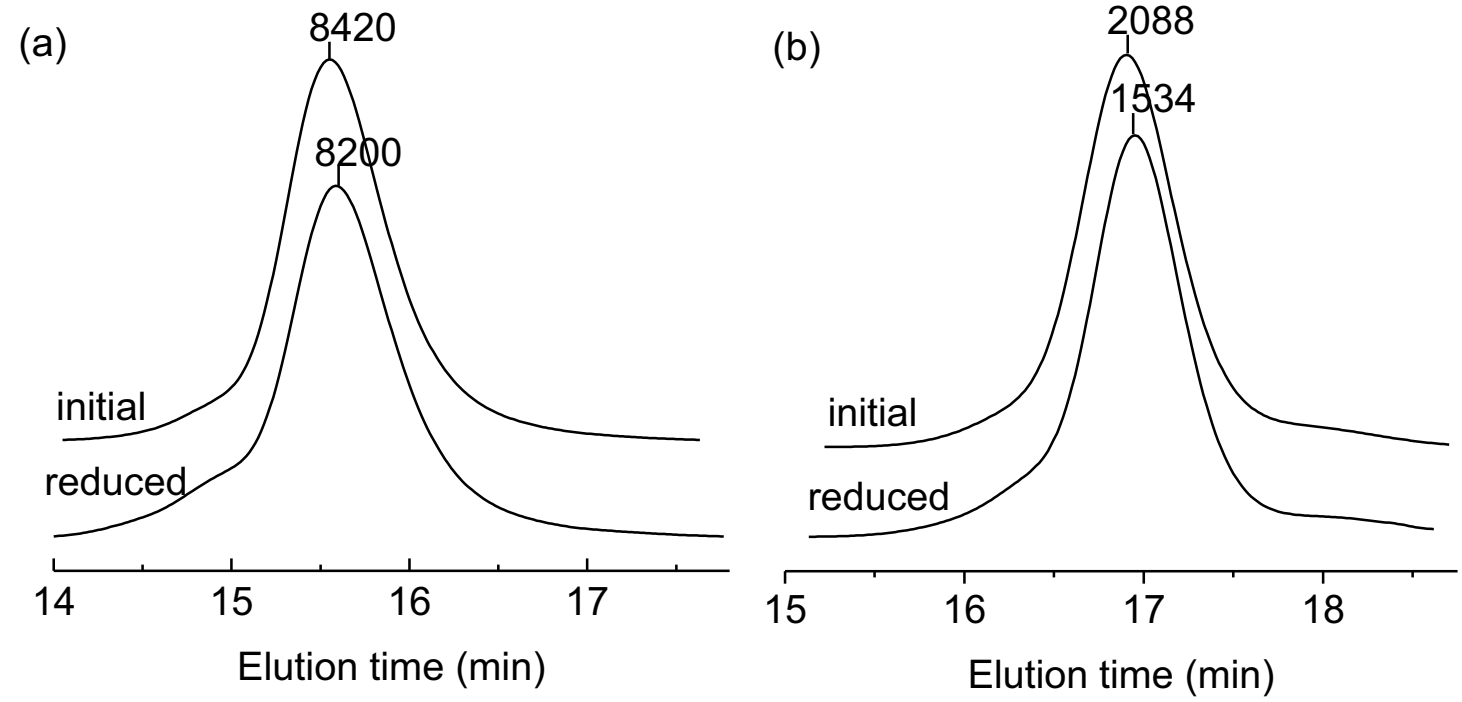

Figure 3. Gel permeation chromatograms for two samples of (a) 3-armed PVAc and (b) 4-armed PVAc and the products obtained by their reduction with dillauroylperoxide in 2-propanol $\left(80^{\circ} \mathrm{C} / 6 \mathrm{~h}\right)$. Peak molecular weights are exhibited on the chromatograms. 
Table 2. Experiment result for the synthesis of linear and multi-armed PVAc

\begin{tabular}{ccccccc}
\hline entry & sample & $\begin{array}{c}M_{\mathrm{n}, \mathrm{theo}} \\
(\mathrm{g} / \mathrm{mol})^{b}\end{array}$ & $\begin{array}{c}M_{\mathrm{n}, \mathrm{GPC}} \\
(\mathrm{g} / \mathrm{mol})(\bigoplus)^{c}\end{array}$ & $\begin{array}{c}\mathrm{DP}^{d} \\
(\mathrm{~g} / \mathrm{mol})^{d}\end{array}$ & $\begin{array}{c}M_{\mathrm{n}, \mathrm{NMR}} \\
\text { end group } \\
\text { removal }(\%)^{d}\end{array}$ \\
\hline 1 & PVAc-X ${ }^{a}$ & 1700 & $1881(1.17)$ & 18 & 1700 & 97.4 \\
2 & PVAc-X & 3400 & $4113(1.27)$ & 42 & 3700 & 96.0 \\
3 & PVAc-X & 5200 & $5563(1.58)$ & 66 & 5800 & 97.1 \\
4 & PVAc3-X & 2200 & $1282(1.29)$ & 12 & 1636 & 98.2 \\
5 & PVAc3-X & 3600 & $2482(1.32)$ & 32 & 3394 & 99.0 \\
6 & PVAc3-X & 2700 & $2947(1.17)$ & 21 & 2374 & 98.7 \\
7 & PVAc3-X & 4400 & $4419(1.15)$ & 41 & 4099 & 96.2 \\
8 & PVAc3-X & 7400 & $8417(1.21)$ & 78 & 7200 & 97.1 \\
9 & PVAc4-X & 2400 & $1534(1.24)$ & 15 & 2090 & 97.2 \\
10 & PVAc4-X & 2900 & $2088(1.23)$ & 25 & 2898 & 96.4 \\
11 & PVAc4-X & 4400 & $3465(1.28)$ & 41 & 4255 & 97.2 \\
12 & PVAc4-X & 5500 & $4303(1.36)$ & 53 & 5249 & 96.9 \\
13 & PVAc4-X & 7200 & $5959(1.34)$ & 77 & 7285 & 96.7 \\
\hline
\end{tabular}

${ }^{a}$ PVAc: linear PVAc, PVAc3: 3-armed PVAc, PVAc4: 4-armed PVAc, X: thiocarbonylthio end-group. ${ }^{b} M_{\mathrm{n} \text {,theoretical }}=[\mathrm{VAc}]_{0} \times M_{w}(\mathrm{VAc}) /[\mathrm{RAFT}]_{0} \times \operatorname{conv}(\mathrm{VAc})+M_{w}(\mathrm{RAFT}) .{ }^{c}$ Determined by GPC in THF with PS standards. ${ }^{d}$ Calculated by ${ }^{1} \mathrm{HNMR}$ in $\mathrm{CDCl}_{3}: \mathrm{DP}=N_{\text {arm }} \times\left(1+\mathrm{d}:\left(\frac{\mathrm{b}}{2}\right)\right), M_{\mathrm{n}, \mathrm{NMR}}=\mathrm{DP} \times M_{w}(\mathrm{VAc})+$ $M_{\mathrm{RAFT}}$, Eff iciency of end group removal $\eta=\left(1-\left(\frac{d}{f}\right)_{\mathrm{after}} /\left(\frac{d}{f}\right)_{\mathrm{before}}\right) \times 100 \%$. The molecular weight of end-removed samples were calculated by the following formula: $M_{\mathrm{n}, \mathrm{rem}}$ $=M_{\mathrm{n}, \mathrm{NMR}} \times[1-M($ end group $) \times \eta]$. The linear PVAc was synthesized by RAFT polymerization with a commercial RAFT agent ( $O$-ethyl-S-(1-methoxycarbonyl) ethyl dithiocarbonate) and the corresponding thiocarbonylthio end-group was also removed.

Previous researchs $[24,46]$ indicated that $\mathrm{CO}_{2}$-philicity of RAFT synthesized polymer could be negatively affected by the thiocarbonylthio group, especially for those with low molecular weight. Moreover, the star structure of the polymer was considered to multiply the end-group effect. We chose dillauroylperoxide (LPO) as the initiator, and 2-propanol as the $\mathrm{H}$ 
atom donor to remove thiocarbonylthio end-groups which had been successfully used by Tong [47]. All the thiocarbonylthio groups could be got rid of after six hours of radical-induced reduction as demonstrated in Figure 1c. Comparing with the former polymer in Figure $1 \mathrm{~b}$, the peaks of $a$ and $b$ on the thiocarbonylthio end groups were clearly disappeared and their influence on the adjacent $\mathrm{H}$ atom reduced. In addition, the signals of protons from the other functional groups remained. GPC analysis shown in Figure 3 also indicated that there was no significant change in the molecular weight distribution and an expected small drop in the molecular weight associated with end group loss was observed.

\subsection{Cloud Point Pressures of PVAc with different molecular structure in $\mathrm{scCO}_{2}$.}

In the high-pressure variable volume view cell, the $P_{\mathrm{c}}$ of the PVAc with different molecular structure and molecular weight in $\mathrm{scCO}_{2}$ were determined at a concentration of 0.2 wt \% PVAc in $\mathrm{CO}_{2}$ and $35^{\circ} \mathrm{C}$. The polymer concentration was chosen to compare with other PVAc/ $\mathrm{CO}_{2}$ studies $[24,25,29]$ and a large amount of polymer loading needed much higher dissolving pressure that would exceed the capacity of our instrumentation. Figures $4 \mathrm{a}$ and $4 \mathrm{~b}$ show the $P_{\mathrm{c}}$ of the PVAc with end group and end-removed PVAc as a function of the molecular weight, respectively. The $M_{\mathrm{n}}$ was varied from 1000 to $7000 \mathrm{~g} / \mathrm{mol}$. For the linear PVAc, the $P_{\mathrm{c}}$ increases with increasing the $M_{\mathrm{n}}$, which is consistent with the literature [29]. However, the $P_{\mathrm{c}}$ versus $M_{\mathrm{n}}$ curves of the multi-armed PVAc followed a different trend. For both 3-armed and 4-armed PVAc, with the increase of $M_{\mathrm{n}}$, the $P_{\mathrm{c}}$ first decreased, and then increased, which exists a lowest pressure at a given $M_{\mathrm{n}}$. The $M_{\mathrm{n}}$ value corresponding to the lowest pressure depended on the molecular chain structure of the PVAc and was in the range 
of $3000-4000 \mathrm{~g} / \mathrm{mol}$. In addition, the $P_{\mathrm{c}}$ declined when increasing the number of arms at high $M_{\mathrm{n}}$, whereas increased at low $M_{\mathrm{n}}$, which indicated the polymer arms were negative to decrease the $P_{\mathrm{c}}$ when $M_{\mathrm{n}}$ was kept at a low level. In other PVAc/ $\mathrm{CO}_{2}$ studies, Cooper et al. [29] also found that linear PVAc with a $M_{\mathrm{n}}$ about $1700 \mathrm{~g} / \mathrm{mol}$ had a lower $P_{\mathrm{c}}$ than the 3-armed PVAc, while Tan et al. [33] claimed that the PVAc with more arms had lower $P_{\mathrm{c}}$ at about $3500 \mathrm{~g} / \mathrm{mol}$. The trends of their results looked contradictory, but had a basic agreement with the results in this work. In addition, the distinction of the trends should be due to the effect of $M_{\mathrm{n}}$ on the $\mathrm{CO}_{2}$-philicity of the PVAc with multi-armed structure. The existence of the minimum value in the cloud point curve of multi-armed PVAc indicated that there were some unfavorable factors such as strong polymer-polymer interactions leading to an increase of the $P_{\mathrm{c}}$ compared with the linear PVAc at low $M_{\mathrm{n}}$. To understand the observed solubility behavior of PVAc with different molecular weight and structure, a respective contributions of polymer-solvent and polymer-polymer interactions were evaluated in the section 4.3 .

Figure 4 also shows that the $P_{\mathrm{c}}$ of the end-removed linear, 3-armed, 4-armed PVAc in $\mathrm{scCO}_{2}$ are lower than those of the corresponding end group non-removed ones. For example, the removal of the end group of the 3-armed PVAc $\left(M_{\mathrm{n}}=4099 \mathrm{~g} / \mathrm{mol}\right)$ would result in $P_{\mathrm{c}}$ decrease from 27.0 to 24.1 MPa. Especially for PVAc at low $M_{\mathrm{n}}$, the end group effect would be more significant reflected by a large decline of $P_{\mathrm{c}}$ after removing the end groups. These results indicated that the thiocarbonylthio groups did harm to the $\mathrm{CO}_{2}$-philicity of the polymer. Thus, the removal of these groups would be helpful to improve the solubility of the PVAc in $\mathrm{scCO}_{2}$. 

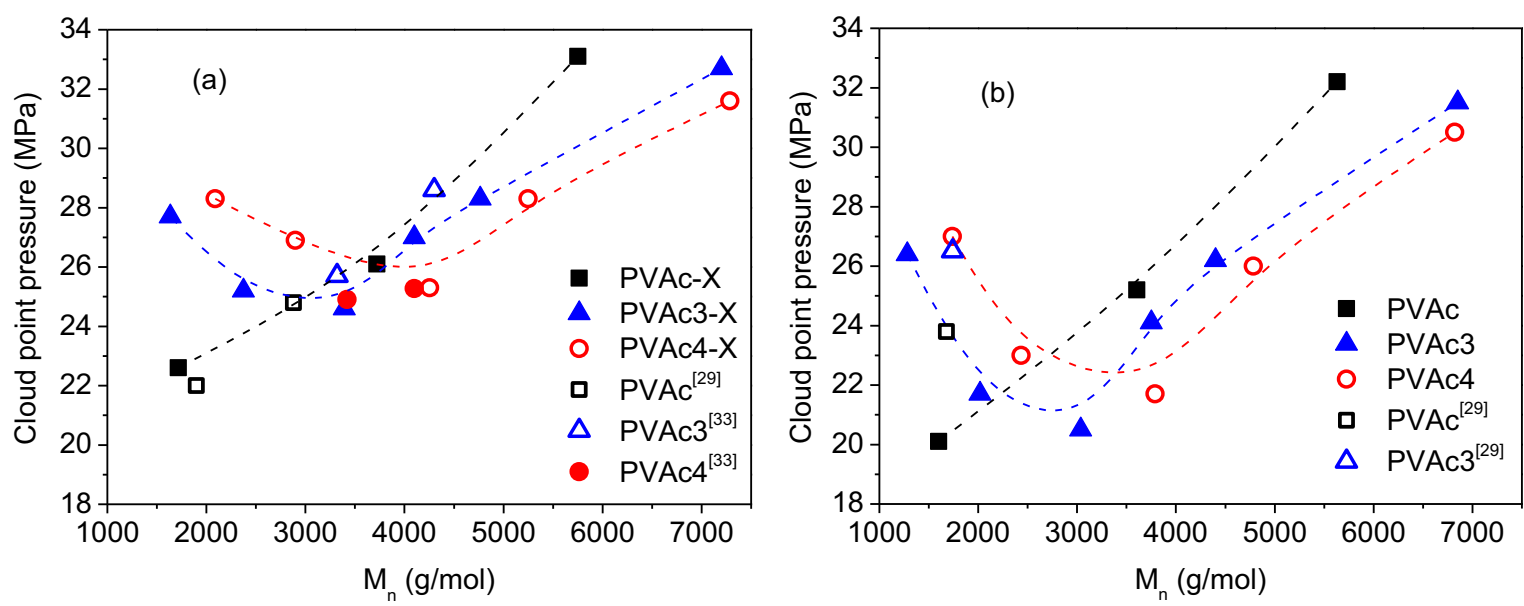

Figure 4. Effect of the molecular weight on the cloud point pressures of (a) PVAc with different molecular structure and (b) the products obtained by their reduction of end groups. The lines only indicated the trend. ( $\triangle$ and $\bigcirc$ were measured at $30{ }^{\circ} \mathrm{C}$ with a polymer amount of $0.1 \mathrm{~g}$ in a $10 \mathrm{~mL}$ cell, and other data points were all measured at $35{ }^{\circ} \mathrm{C}$ with a concentration of $0.2 \mathrm{wt} \% \mathrm{CO}_{2}$ ).

\subsection{Models and simulations}

\subsubsection{Polymer Chain- $\mathrm{CO}_{2}$ Interaction}

In a polymer/ $\mathrm{CO}_{2}$ system, the polymer- $\mathrm{CO}_{2}$ and polymer-polymer interactions exist simultaneously and affect each other. In order to exclude the impact of polymer-polymer interaction and offer a clearer understanding on the effect of the multi-armed structure on the interaction between polymer and $\mathrm{CO}_{2}$, the simulation box containing only one polymer chain and $1000 \mathrm{CO}_{2}$ molecules (systems 6 to 10 in Table 1) was introduced to evaluate the polymer- $\mathrm{CO}_{2}$ interaction by using $\mathrm{MD}$ calculations.

Table 3. Interaction energy between a single polymer chain and $1000 \mathrm{CO}_{2}$ molecules. $(\mathrm{kJ} / \mathrm{mol})$

\begin{tabular}{ccccc} 
System & $E_{\text {inter }}$ & $E_{\mathrm{vdW}}$ & $E_{\text {electro }}$ & $E_{\text {inter-single }}$ \\
\hline PVAc $_{30}$ & -673.5 & -535.0 & -138.6 & -22.5 \\
$\mathrm{PVAc}_{30-3}$ & -688.6 & -542.0 & -146.6 & -23.0 \\
$\mathrm{PVAc}_{30-4}$ & -707.4 & -570.0 & -137.4 & -23.6 \\
\hline
\end{tabular}




\begin{tabular}{ccccc}
\hline PVAc $_{38}$ & -819.5 & -668.0 & -151.6 & -21.6 \\
PVAc$_{38-3}$ & -846.8 & -686.0 & -160.7 & -22.3 \\
PVAc $_{38-4}$ & -889.5 & -701.4 & -188.1 & -23.4 \\
\hline PVAc $_{50}$ & -1169.5 & -915.0 & -254.6 & -23.4 \\
PVAc $_{50-3}$ & -1194.4 & -921.7 & -272.8 & -23.9 \\
PVAc $_{50-4}$ & -1210.1 & -951.6 & -258.5 & -24.2 \\
\hline PVAc $_{60}$ & -1472.6 & -1122.1 & -350.5 & -24.5 \\
PVAc$_{60-3}$ & -1505.7 & -1182.5 & -323.1 & -25.1 \\
PVAc $_{60-4}$ & -1621.1 & -1220.6 & -400.5 & -27.0 \\
\hline PVAc $_{75}$ & -1730.3 & -1209.0 & -521.3 & -23.1 \\
PVAc $_{75-3}$ & -1807.5 & -1312.7 & -494.8 & -24.1 \\
PVAc$_{75-4}$ & -1839.6 & -1338.5 & -501.1 & -24.5 \\
\hline
\end{tabular}

The polymer chain- $\mathrm{CO}_{2}$ interaction can be quantitatively evaluated through calculation of the binding energies between the polymer chain and $\mathrm{CO}_{2}$. The binding energies can reflect the binding strength between the polymer chain and $\mathrm{CO}_{2}$. The binding energy in a polymer chain- $\mathrm{CO}_{2}$ system was calculated from the energy analysis of the simulation results in Forcite program, expressed as follows:

$E_{\text {inter }}=-E_{\text {binding }}=E_{\text {chain/ } \mathrm{CO}_{2}}-\left(E_{\text {chain }}+E_{\mathrm{CO}_{2}}\right)$

where $E_{\text {inter }}$ and $E_{\text {binding }}$ referred to the interaction energy and the binging energy between $\mathrm{CO}_{2}$ and a single polymer chain. $E_{\text {chain/CO2 }}$ represented the energy of polymer chain/ $/ \mathrm{CO}_{2}$ system. $E_{\mathrm{CO} 2}$ and $E_{\text {chain }}$ were the energies of $\mathrm{CO}_{2}$ and the polymer chain in the system, respectively. Table 3 shows the calculated results of the interaction energy between $\mathrm{CO}_{2}$ and the polymer chains with different $M_{\mathrm{n}}$ and molecular structure. More details about the simulated results of $E_{\text {chain/CO2}}, E_{\mathrm{CO} 2}$ and $E_{\text {chain }}$ can be found in Table $\mathrm{S} 2$ of the Supporting Information.

The interaction energies between $\mathrm{CO}_{2}$ and multi-armed PVAc chains were stronger than 
that of linear PVAc chain with the same $M_{\mathrm{n}}$, and the interaction energy between $\mathrm{CO}_{2}$ and the 4-armed structures was the largest at the same $M_{\mathrm{n}}$, indicating that the multi-armed structure was favorable to enhance the interaction and compatibility between $\mathrm{CO}_{2}$ and polymer. The interaction energy was attributed to two kinds of interaction, comprising van der Waals force and electrostatic force, denoted as $E_{\mathrm{vdW}}$ and $E_{\text {electro, }}$ respectively. The van der Waals energy was predominant interaction between $\mathrm{CO}_{2}$ and polymer, as illustrated in Table 3, and the variation tendency of the $E_{\mathrm{vdW}}$ was consistent with that of $E_{\text {inter }}$. The $E_{\text {inter }}$ was enhanced with the increase of $M_{\mathrm{n}}$ due to the more interaction point between $\mathrm{CO}_{2}$ and the polymer with increased repeat units. The average interaction energy between $\mathrm{CO}_{2}$ and each repeating unit in

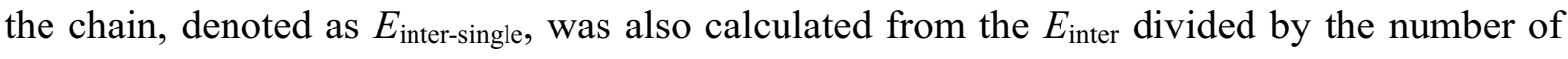
repeating units. The $E_{\text {inter-single }}$ was almost in the range of $22-27 \mathrm{~kJ} / \mathrm{mol}$ and changed little with different $M_{\mathrm{n}}$. In our previous work [42], the interaction energy between VAc dimer and $\mathrm{CO}_{2}$ was studied by using the ab initio method. In the stable configuration, the carbon atom of $\mathrm{CO}_{2}$ was placed between carbonyl oxygen in one repeat unit and ether oxygen in the other repeat unit, and the interaction energy was $21.3 \mathrm{~kJ} / \mathrm{mol}$. The results of $E_{\text {inter-single }}$ were all slightly larger than the interaction energy between VAc dimer and a $\mathrm{CO}_{2}$ molecule calculated by the $a b$ initio method, which was reasonable since more $\mathrm{CO}_{2}$ molecules could place in more different positions near the polymer chain and cause stronger interaction between $\mathrm{CO}_{2}$ and polymer chain in MD simulations. In conclusion, the van der Waals interaction dominates the interaction of polymer chain/ $\mathrm{CO}_{2}$ system, and the multi-armed structure can enhance the interaction between $\mathrm{CO}_{2}$ and polymer chain, which is always favorable to the compatibility 
between polymer and $\mathrm{CO}_{2}$.

\subsubsection{Polymer-Polymer Interaction}

Besides the polymer- $\mathrm{CO}_{2}$ interactions, the polymer-polymer interaction has strong influence on the compatibility of polymer with $\mathrm{CO}_{2}$. Moderate polymer-polymer interaction is essential for its dissolution in $\mathrm{CO}_{2}$. The cohesive energy $\left(E_{\text {coh }}\right)$ was an important criterion to evaluate the inter-molecular force of polymer. CED, denoted as $e_{\mathrm{coh}}$, is the ratio between $E_{\mathrm{coh}}$ and the volume of polymer, $V$, according to:

$e_{\mathrm{coh}}=E_{\mathrm{coh}} / V$

Additionally, the Hildebrand solubility parameter is described as the square root of CED, expressed as follows:

$\delta=\sqrt{e_{\mathrm{coh}}}=\sqrt{E_{\mathrm{coh}} / V}$

where $\delta$ represented the solubility parameter. In general, the value of CED could characterize quantitatively to describe the intermolecular interaction between polymer chains. To investigate the effect of molecular structure and $M_{\mathrm{n}}$ on the CED and solubility parameter of polymer, linear and multi-armed PVAc system with different $M_{\mathrm{n}}$ were simulated by using MD method. There was different number of polymer chains but similar total repeat units in the simulation boxes. The number of repeat units and chains in different cases was listed as systems 1 to 5 in Table 1 .

Figure 5 shows the calculated results of CED and solubility parameter analyzing from the trajectories of final $50 \mathrm{ps}$ in MD simulations. The more details about the data of CED and 
density are listed in Table S3 of the Supporting Information. In general, the number of monomer repeat units of polymer chain had a significant effect on the CED and solubility parameter, especially at the low $M_{\mathrm{n}}$. In the $M_{\mathrm{n}}$ range in this work, the $e_{\text {coh }}$ and $\delta$ decreased slowly with increasing the $M_{\mathrm{n}}$ of PVAc with different molecular structures, which is consistent with the relationship between the calculated solubility parameter and the number of repeat units for some other polymers $[48,49]$. The $e_{\mathrm{coh}}$ of the 4-armed PVAc was larger than those of the 3-armed PVAc and linear PVAc at the $M_{\mathrm{n}}$ of $2580 \mathrm{~g} / \mathrm{mol}$. The multi-armed structure enhanced intermolecular interactions between polymer chains, which might be caused by the increase of end groups. The difference in $e_{\text {coh }}$ between different molecular structures was significantly reduced at the $M_{\mathrm{n}}$ of $4300 \mathrm{~g} / \mathrm{mol}$. In contrast, the $e_{\mathrm{coh}}$ of the linear PVAc was greater than that of the multi-armed PVAc when the $M_{\mathrm{n}}$ of the polymer was increased to 5000 $\mathrm{g} / \mathrm{mol}$. Multi-armed structure led to more moderate polymer-polymer interaction when the chain length of polymer reached an enough size. It could be attributed to the reduction of chain entanglement in the presence of branched chains.

According to the principle of "like dissolves like", the polymer with a similar solubility parameter to $\mathrm{CO}_{2}$, tends to have a good compatibility with $\mathrm{CO}_{2}$. In general, the $\delta$ values of polymers are always larger than that of $\mathrm{CO}_{2}$. The $\delta$ value of $\mathrm{CO}_{2}$ was 13.10 at $20 \mathrm{MPa}$ and $35^{\circ} \mathrm{C}$, calculated by MD simulations in our previous work [43]. As shown in Figure 5(b), it can be seen that the $\delta$ of the linear PVAc was closer to that of $\mathrm{CO}_{2}$ at the $M_{\mathrm{n}}$ of $2580 \mathrm{~g} / \mathrm{mol}$ while the $\delta$ of the 4-armed PVAc was closer to that of $\mathrm{CO}_{2}$ at the $M_{\mathrm{n}}$ larger than $5000 \mathrm{~g} / \mathrm{mol}$, indicating that linear PVAc had a better compatibility at $2580 \mathrm{~g} / \mathrm{mol}$ but had a poorer 
compatibility at above $5000 \mathrm{~g} / \mathrm{mol}$ with $\mathrm{CO}_{2}$ than the multi-armed PVAc. From the viewpoint of PVAc chain self-interaction, the multi-armed structure had different effects on the compatibility with $\mathrm{CO}_{2}$ at different $M_{\mathrm{n}}$ range. At the high $M_{\mathrm{n}}$, the multi-armed PVAc should be a better candidate for enhancing the solubility and decrease the $P_{\mathrm{c}}$ in $\mathrm{CO}_{2}$.
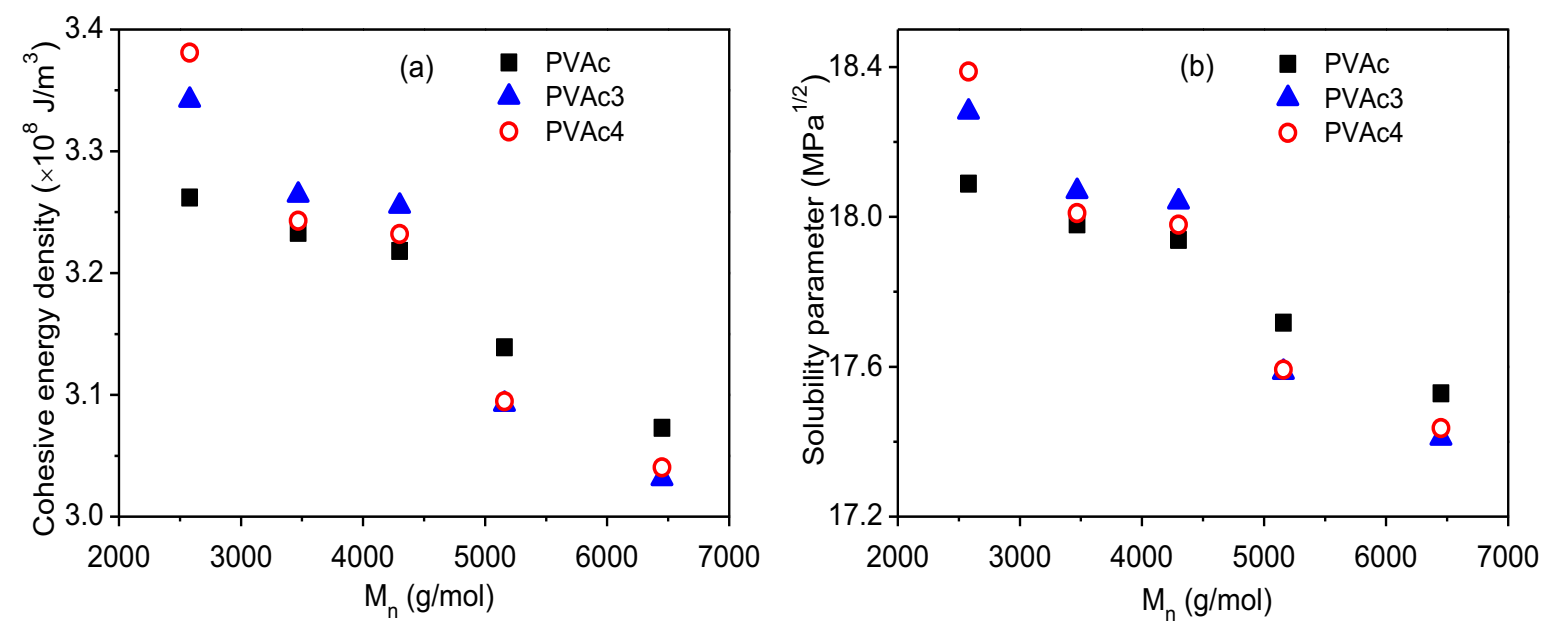

Figure 5. Effect of $M_{\mathrm{n}}$ on simulated CED and solubility parameter of PVAc with different structures.

The contribution of polymer-polymer interactions was also evaluated from surface tension which was commonly measured with sessile drop measurements. The surface tensions of the polymers were obtained by water contact angle through the empirical formula proposed by Li and Neumann [50] and the experimental method was the same as Girard et al. [28] (see Table S1 in the Supporting Information). The larger surface tension indicated the stronger polymer-polymer interaction $[13,23]$. As shown in Figure 6, increase in the molecular weight would result in a decline of surface tension at the molecular weight between 1000 and 7000 $\mathrm{g} / \mathrm{mol}$. The surface tension of the multi-armed PVAc decreased more significantly with increasing the molecular weight than that of the linear PVAc. At low $M_{\mathrm{n}}$, the surface tension of the multi-armed PVAc was higher than that of the linear one, indicating that the 
polymer-polymer interactions of multi-armed PVAc were stronger than that of the linear one and might weaken the $\mathrm{CO}_{2}$-philicity of multi-armed PVAc. However, the polymer-polymer interactions of multi-armed PVAc sharply reduced with further increasing the molecular weight comparing to linear PVAc, which might lead to the enhancement of $\mathrm{CO}_{2}$-philicity. The results were basically consistent with the simulation results and evidenced that the important impact of polymer-polymer interactions on the polymer $\mathrm{CO}_{2}$-philicity.

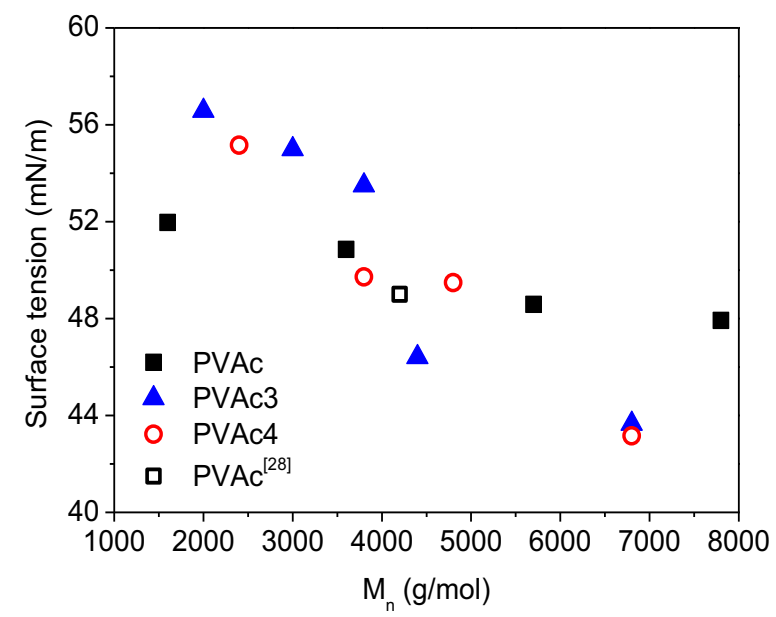

Figure 6. The surface tension of PVAc with different molecular structure and molecular weight.

\subsubsection{Flory-Huggins Interaction Parameter}

Actually, the polymer- $\mathrm{CO}_{2}$ interaction and polymer-polymer interaction occur simultaneously and cannot be separated from each other in the real polymer/ $\mathrm{CO}_{2}$ systems. In order to provide a complete understanding of the compatibility between polymer and $\mathrm{CO}_{2}$, the Flory-Huggins interaction parameter was introduced to estimate the $\mathrm{CO}_{2}$-philicity of polymers. This parameter, denoted as $\chi_{12}$, contained simultaneously the factor of polymer- $\mathrm{CO}_{2}$ interaction and that of polymer-polymer interaction. The $\chi_{12}$ could be calculated from the following equation: 
$\chi_{12}=\left(\frac{\Delta E_{\text {mix }}}{R T \varphi_{\mathrm{A}} \varphi_{\mathrm{B}}}\right) V_{\mathrm{m}}$

where $R$ and $T$ referred to the molar gas constant and the temperature in Kelvin, respectively. $V_{\mathrm{m}}$ was the reference mole volume. $\varphi_{\mathrm{A}}$ and $\varphi_{\mathrm{B}}$ were the volume fractions of polymer and $\mathrm{CO}_{2}$ in the polymer $/ \mathrm{CO}_{2}$ system, respectively. $\Delta E_{\text {mix }}$ represented the mixing energy between polymer and $\mathrm{CO}_{2}$, which could be evaluated by the following equation:

$\Delta E_{\text {mix }}=\varphi_{\mathrm{A}} e_{\text {coh }, \mathrm{A}}+\varphi_{\mathrm{B}} e_{\mathrm{coh}, \mathrm{B}}-e_{\mathrm{coh}, \mathrm{mix}}$

where $e_{\mathrm{cob}, \mathrm{A}}$ and $e_{\mathrm{coh}, \mathrm{B}}$ were the $\mathrm{CED}$ of polymer and $\mathrm{CO}_{2}$, respectively. $e_{\mathrm{coh}, \text { mix }}$ represented the $\mathrm{CED}$ of the polymer $/ \mathrm{CO}_{2}$ system, and the data of polymer $/ \mathrm{CO}_{2}$ system density were listed in Table S4 of the Supporting Information. The critical value of miscibility criterion $\chi_{\mathrm{c}}$ can be calculated by eq 6 :

$\chi_{\mathrm{c}}=\frac{1}{2}\left(1+\frac{1}{\sqrt{n}}\right)^{2}$

where $n$ was the number of repeat units in the polymer chain. When $\chi_{12}$ of the mixture was smaller than $\chi_{\mathrm{c}}$, the system is considered to be miscible well. For the same number of repeat units, the smaller $\chi_{12}$ suggested the more miscible binary system. The critical value of miscibility, $\chi_{c}$, was all ranging from 0.62 to 0.70 due to the number of repeat units in this work.

Figure 7 illustrates the values of $\chi_{12}$ between $\mathrm{CO}_{2}$ and PVAc with different $M_{\mathrm{n}}$ and different structures calculated by using eq.(4). The results showed that all the $\chi_{12}$ of the $\mathrm{PVAc} / \mathrm{CO}_{2}$ systems were higher than the critical value, indicating a poor compatibility between PVAc and $\mathrm{CO}_{2}$, which was consistent with the fact that $\mathrm{CO}_{2}$ was a weak solvent for 
polymers. By comparing the $\chi_{12}$ in these $\mathrm{PVAc} / \mathrm{CO}_{2}$ systems, it could be found that the $\chi_{12}$ of linear PVAc was lower than that of the multi-armed PVAc systems at $2580 \mathrm{~g} / \mathrm{mol}$, proposing that multi-armed PVAc was not a good choice to enhance the compatibility of PVAc with $\mathrm{CO}_{2}$, which agreed well with the experiment results of the $P_{\mathrm{c}}$ in $\mathrm{CO}_{2}$. At the small $M_{\mathrm{n}}$, the difference of CED is significant between different molecular chain structure, and the CED was the main driving force deciding the $\mathrm{CO}_{2}$-philicity. With increasing the $M_{\mathrm{n}}$, the difference of CED reduced between different molecular chain structures, and the difference of $\chi_{12}$ was also smaller. When the $M_{\mathrm{n}}$ was larger than $5000 \mathrm{~g} / \mathrm{mol}$, the $\chi_{12}$ of linear PVAc was larger than that of the multi-armed PVAc systems, indicating that the multi-armed PVAc was a better choice for the dissolution of PVAc in $\mathrm{CO}_{2}$. The conclusion also agreed well with the experiment results. From the simulation results, at high $M_{\mathrm{n}}$, the multi-armed structure was favorable to the $\mathrm{CO}_{2}$-philicity due to the synergistic effect of more moderate polymer-polymer interaction and stronger polymer- $\mathrm{CO}_{2}$ interaction.

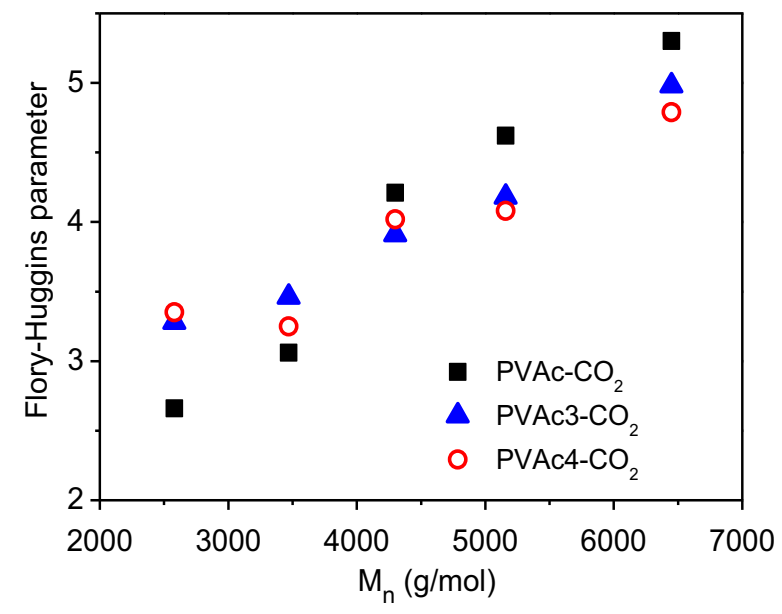

Figure 7. Flory-Huggins interaction parameter between $\mathrm{CO}_{2}$ and $\mathrm{PVAc}$ with different $M_{\mathrm{n}}$ and different structures 


\subsubsection{Radial distribution functions}

To obtain a more thorough understanding of the polymer-polymer and polymer- $\mathrm{CO}_{2}$ interactions in the polymer/ $\mathrm{CO}_{2}$ system, radial distribution function, denoted as $g(r)$, was introduced to analyze the simulation result after MD calculations. This function describes how density varies as a function of distance from a reference particle and reflects the micro-structural characteristics, which is a useful analysis method in the structural characterizations to study the regularity of specific interactions between the particles (atoms, molecules, colloids, etc.) in the system. It was defined as:

$g_{\mathrm{AB}}(r)=\frac{\left\langle n_{\mathrm{AB}}(r)\right\rangle}{\rho_{\mathrm{AB}} \cdot 4 \pi r^{2} \cdot \Delta r}$

where $g_{\mathrm{AB}}(r)$ represented the radial distribution function, and the subscripts A and B referred to two kinds of particles. $\left\langle n_{\mathrm{AB}}(r)\right\rangle$ was the average number of atom pairs in a distance interval $\Delta r$ between $r$ and $r+\Delta r . \rho_{\mathrm{AB}}$ referred to the density of atom pairs of $\mathrm{AB}$. The inter-molecular $g(r)$ was related to the correlations of molecular arrangement between different molecules or chains to evaluate the compatibility between polymer and $\mathrm{CO}_{2}[51]$.

The $g(r)$ of intermolecular carbon atomic pairs for PVAc chains with different molecular structures are plotted in Figure 8 . Here we only show the $g(r)$ of pure polymer systems, system 1, 3 and 5 in Table 1 , corresponding to the $M_{\mathrm{n}}$ of 2580,4300 and $6450 \mathrm{~g} / \mathrm{mol}$. As shown in Figure 8, no sharp peaks were observed in the curves of $g(r)$, indicating that the $\mathrm{C}$ atoms of two different polymer chains were not systematically arranged in order at a $r$ distance from one another, which agreed well with the amorphous structure of PVAc. At the 
$M_{\mathrm{n}}$ of $2580 \mathrm{~g} / \mathrm{mol}$, the $g(r)$ intensities of multi-armed PVAc were higher than that of linear PVAc on a same distance, indicating that the $\mathrm{C}$ atoms of multi-armed PVAc were more closely surrounded by other polymer chains. It was a strong indicator that the chain interactions of multi-armed PVAc, as well as the C-C atom pair interactions, were stronger at this $M_{\mathrm{n}}$. However, the $g(r)$ curves had significant differences at the $M_{\mathrm{n}}$ of $6450 \mathrm{~g} / \mathrm{mol}$. The $g(r)$ values of linear PVAc were higher than that of multi-armed PVAc at a same distance, indicating that the polymer-polymer interaction of linear PVAc was stronger at this $M_{\mathrm{n}}$. The results of $g(r)$ were also consistent with the tendency of CED calculated in MD simulations, which was self-consistent with the inherent logic of interaction between polymer chains.
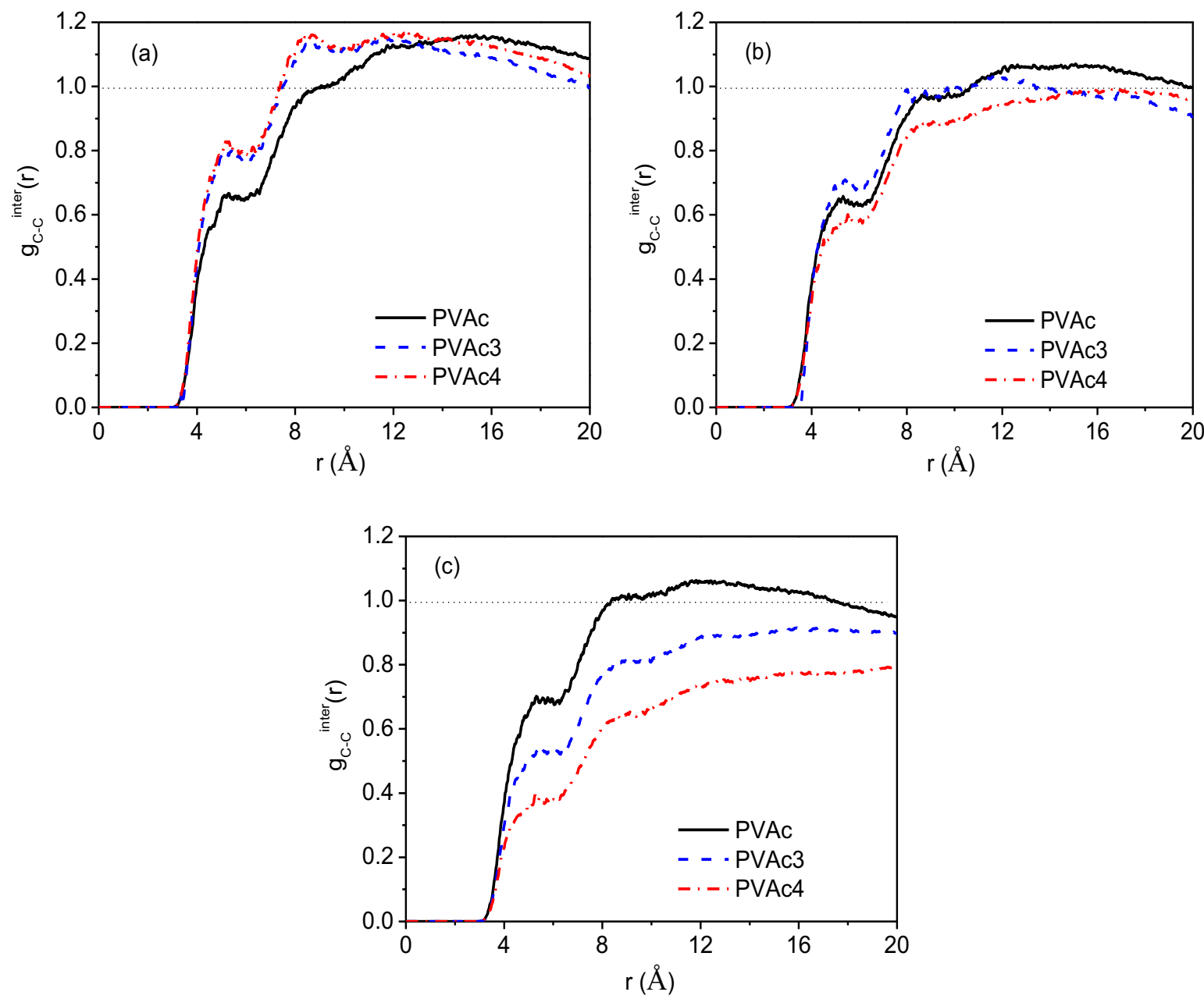

Figure 8. Intermolecular distribution for the C-C pairs in PVAc with different $M_{\mathrm{n}}$ and different 
structures.(a) $2580 \mathrm{~g} / \mathrm{mol}$; (b) 4300g/mol; (c) $6450 \mathrm{~g} / \mathrm{mol}$.

The $g(r)$ of intermolecular $\mathrm{C}-\mathrm{C}$ atom pairs between polymer and $\mathrm{CO}_{2}$ were also calculated from the simulation results of the systems 11, 13 and 15 in Table 1. As shown in Figure 9, at the $M_{\mathrm{n}}$ of $2580 \mathrm{~g} / \mathrm{mol}$, the $g(r)$ of C-C atom pairs between $\mathrm{CO}_{2}$ and linear PVAc were slightly higher than that between $\mathrm{CO}_{2}$ and multi-armed PVAc on a same distance. It was proposed that the $\mathrm{C}$ atoms of $\mathrm{CO}_{2}$ could contact linear PVAc more closely due to the weaker contact between polymer chains of linear PVAc. At the $M_{\mathrm{n}}$ of $4300 \mathrm{~g} / \mathrm{mol}$, the differences of $g(r)$ were very small in PVAc with different molecular structures. However, at the $M_{\mathrm{n}}$ of 6450 $\mathrm{g} / \mathrm{mol}$, the $g(r)$ values of $\mathrm{C}-\mathrm{C}$ atom pairs between $\mathrm{CO}_{2}$ and linear PVAc were lower than that between $\mathrm{CO}_{2}$ and multi-armed PVAc on a same distance. The difference of tendency in $g(r)$ could also be attributed to the polymer-polymer interactions caused by the different molecular structures at different $M_{\mathrm{n}}$. Thus, with different $M_{\mathrm{n}}$, there was a big difference in the effect of polymer molecular structures on the $\mathrm{CO}_{2}$-philicity. The comparisons of $g(r)$ values offered a deeper understanding on the interactions of polymer/ $\mathrm{CO}_{2}$ systems at the molecular level. Within a certain range of the $M_{\mathrm{n}}$, the appropriate molecular structure could be selected to enhance the $\mathrm{CO}_{2}$-philicity of PVAc. 

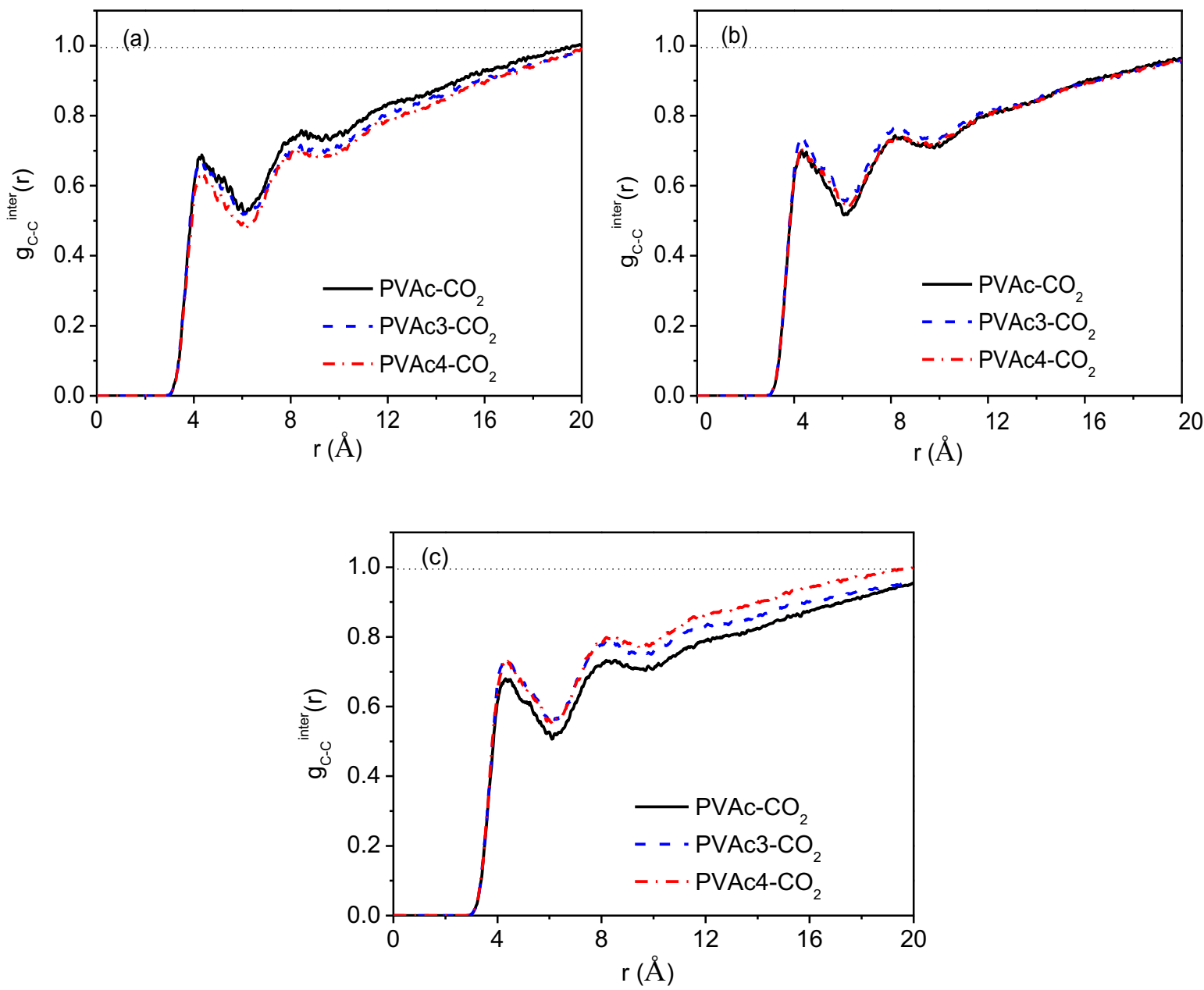

Figure 9. Intermolecular distribution for the $\mathrm{C}-\mathrm{C}$ pairs between polymer chains and $\mathrm{CO}_{2}$. (a) $2580 \mathrm{~g} / \mathrm{mol}$; (b) $4300 \mathrm{~g} / \mathrm{mol}$; (c) $6450 \mathrm{~g} / \mathrm{mol}$.

\section{CONCLUSION}

The linear, 3-armed and 4-armed R-core PVAc was synthesized by RAFT polymerization with well-defined $M_{\mathrm{n}}$ distributions, and then the corresponding xanthate groups were removed. The $\mathrm{CO}_{2}$-philicity of the multi-armed PVAc was found to be inferior to that of the linear one at low $M_{\mathrm{n}}$. With increasing the $M_{\mathrm{n}}$ from 1000 to $7000 \mathrm{~g} / \mathrm{mol}$, the $P_{\mathrm{c}}$ of both 3-armed and 4-armed PVAc first decreased, reached a minimum at a given $M_{\mathrm{n}}$, which was lower than that of the linear PVAc, and then increased. It was different from the variation trend of the $P_{\mathrm{c}}$ of 
linear PVAc versus $M_{\mathrm{n}}$. In addition, removal of the xanthate groups could effectively enhance the $\mathrm{CO}_{2}$-philicity of PVAc, especially at low $M_{\mathrm{n}}$.

The MD simulations proposed that the multi-armed structures could enhance the interaction between $\mathrm{CO}_{2}$ and polymer. However, they had different effects on the CED of polymer at different $M_{\mathrm{n}}$ range. The CED of the multi-armed PVAc was larger than that of the linear one at the low $M_{\mathrm{n}}$ while the trend of CED was the opposite at the high $M_{\mathrm{n}}$. Meanwhile, the variation trend of calculated CED versus $M_{\mathrm{n}}$ had a good agreement with that of the surface tension versus $M_{\mathrm{n}}$, reflecting the polymer-polymer interaction. At low $M_{\mathrm{n}}$, the polymer-polymer interaction was the main driving force to lead the better $\mathrm{CO}_{2}$-philicity of linear PVAc while the multi-armed structure enhanced the $\mathrm{CO}_{2}$-philicity due to the synergistic effect of moderate polymer-polymer interaction and large polymer- $\mathrm{CO}_{2}$ interaction at the high $M_{\mathrm{n}}$. The $g(r)$ of PVAc/ $/ \mathrm{CO}_{2}$ systems with different $M_{\mathrm{n}}$ also confirmed that the tendency of polymer self-interaction and $\mathrm{CO}_{2}$-philicity of PVAc were difference caused by the different molecular structures at different $M_{\mathrm{n}}$, which offered a deeper understanding on the interactions of polymer $/ \mathrm{CO}_{2}$ systems at the molecular level. Within a certain range of the $M_{\mathrm{n}}$, the appropriate molecular structure could be selected to enhance the $\mathrm{CO}_{2}$-philicity of PVAc.

\section{ACKNOWLEDGMENTS}

This work was supported by the National Science Foundation of China (21376087), Research Fund for the Doctoral Program of Higher Education of China (20130074110013), the 111 Project (B08021), and the Fundamental Research Funds for the Central Universities.

\section{REFERENCES}


[1] J.M. DeSimone, Practical Approaches to Green Solvents, Science, 297 (2002) 799-803.

[2] C. Capello, U. Fischer, K. Hungerbühler, What is a green solvent? A comprehensive framework for the environmental assessment of solvents, Green Chem. 9 (2007) 927-934.

[3] K. Liu, F. Schuch, E. Kiran, High-pressure viscosity and density of poly(methyl methacrylate) + acetone and poly (methyl methacrylate) + acetone $+\mathrm{CO}_{2}$ systems, J. Supercrit. Fluids 39 (2006) 89-101.

[4] D.L. Tomasko, H. Li, D. Liu, X. Han, M.J. Wingert, L.J. Lee, K.W. Koelling, A review of $\mathrm{CO}_{2}$ applications in the processing of polymers, Ind. Eng. Chem. Res. 42 (2003) 6431-6456.

[5] S.P. Nalawade, F. Picchioni, L. Janssen, Supercritical carbon dioxide as a green solvent for processing polymer melts: Processing aspects and applications, Prog. Polym. Sci. 31 (2006) 19-43.

[6] K. Liu, E. Kiran, High-pressure solution blending of poly(e-caprolactone) with poly(methyl methacrylate) in acetone + carbon dioxide, Polymer 49 (2008) 1555-1561.

[7] J. Eastoe, B.M. Cazelles, D.C. Steytler, J.D. Holmes, A.R. Pitt, T.J. Wear, R.K. Heenan, Water-in- $\mathrm{CO}_{2}$ microemulsions studied by small-angle neutron scattering, Langmuir 13 (1997) 6980-6984.

[8] Z. Huang, C. Shi, J. Xu, S. Kilic, R.M. Enick, E.J. Beckman, Enhancement of the viscosity of carbon dioxide using styrene/fluoroacrylate copolymers, Macromolecules 33 (2000) 5437-5442.

[9] R. Mertsch, B.A. Wolf, Solutions of Poly(dimethylsiloxane) in Supercritical $\mathrm{CO}_{2}$ : Viscometric and Volumetric Behavior, Macromolecules 27 (1994) 3289-3294.

[10] E. Beckman, A challenge for green chemistry: designing molecules that readily dissolve in carbon dioxide, Chem. Commun. (2004) 1885-1888.

[11] J. DeSimone, Z. Guan, C. Elsbernd, Synthesis of fluoropolymers in supercritical carbon dioxide, Science 257 (1992) 945-947.

[12] J. DeSimone, E. Maury, Y. Menceloglu, J. McClain, T. Romack, J. Combes, Dispersion polymerizations in supercritical carbon dioxide, Science 265 (1994) 356-359.

[13] M. O'neill, Q. Cao, M. Fang, K. Johnston, S. Wilkinson, C. Smith, J. Kerschner, S. Jureller, Solubility of homopolymers and copolymers in carbon dioxide, Ind. Eng. Chem. Res. 37 (1998) 3067-3079.

[14] C. Drohmann, E.J. Beckman, Phase behavior of polymers containing ether groups in carbon dioxide, J. Supercrit. Fluids 22 (2002) 103-110.

[15] C.L. Bray, B. Tan, S. Higgins, A.I. Cooper, Polymer $\mathrm{CO}_{2}$ Solubility Structure/Property Relationships in Polyester Libraries, Macromolecules 43 (2010) 9426-9433.

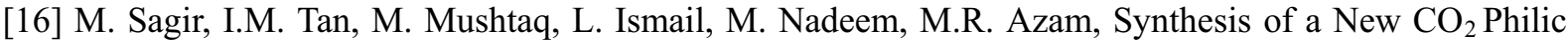
Surfactant for Enhanced Oil Recovery Applications, J. Disper. Sci. Technol., 35 (2014) 647-654.

[17] Z. Shen, M.A. McHugh, J. Xu, J. Belardi, S. Kilic, A. Mesiano, S. Bane, C. Karnikas, E. Beckman, R. Enick, $\mathrm{CO}_{2}$-solubility of oligomers and polymers that contain the carbonyl group, Polymer 44 (2003) 1491-1498.

[18] T. Sarbu, T.J. Styranec, E.J. Beckman, Design and synthesis of low cost, sustainable $\mathrm{CO}_{2}$-philes, Ind. Eng. Chem. Res. 39 (2000) 4678-4683.

[19] S.G. Kazarian, M.F. Vincent, F.V. Bright, C.L. Liotta, C.A. Eckert, Specific intermolecular interaction of carbon dioxide with polymers, J. Am. Chem. Soc. 118 (1996) 1729-1736.

[20] P. Raveendran, S.L. Wallen, Cooperative CH---O Hydrogen Bonding in $\mathrm{CO}_{2}$-Lewis Base Complexes: Implications for Solvation in Supercritical $\mathrm{CO}_{2}$, J. Am. Chem. Soc. 124 (2002) 12590-12599.

[21] B. Baradie, M.S. Shoichet, Z. Shen, M.A. McHugh, L. Hong, Y. Wang, J.K. Johnson, E.J. Beckman, 
R.M. Enick, Synthesis and Solubility of Linear Poly(tetrafluoroethylene-co-vinyl acetate) in Dense $\mathrm{CO}_{2}$ : Experimental and Molecular Modeling Results, Macromolecules 37 (2004) 7799-7807.

[22] F. Rindfleisch, T.P. DiNoia, M.A. McHugh, Solubility of polymers and copolymers in supercritical $\mathrm{CO}_{2}$, J. Phys. Chem. 100 (1996) 15581-15587.

[23] E. Girard, T. Tassaing, S.v. Camy, J.-S.p. Condoret, J.-D. Marty, M. Destarac, Enhancement of Poly(vinyl ester) Solubility in Supercritical $\mathrm{CO}_{2}$ by Partial Fluorination: The Key Role of Polymer-Polymer Interactions, J. Am. Chem. Soc. 134 (2012) 11920-11923.

[24] H. Lee, J.W. Pack, W. Wang, K.J. Thurecht, S.M. Howdle, Synthesis and Phase Behavior of $\mathrm{CO}_{2}$-Soluble Hydrocarbon Copolymer: Poly(vinyl acetate-alt-dibutyl maleate), Macromolecules 43 (2010) 2276-2282

[25] D. Hu, S. Sun, P. Yuan, L. Zhao, T. Liu, Evaluation of $\mathrm{CO}_{2}$-philicity of poly(vinyl acetate) and poly(vinyl acetate-alt-maleate) copolymers through molecular modeling and dissolution behavior measurement, J. Phys. Chem. B 119 (2015) 3194-3204.

[26] H. Lee, E. Terry, M. Zong, N. Arrowsmith, S. Perrier, K.J. Thurecht, S.M. Howdle, Successful Dispersion Polymerization in Supercritical $\mathrm{CO}_{2}$ Using Polyvinylalkylate Hydrocarbon Surfactants Synthesized and Anchored via RAFT, J. Am. Chem. Soc. 130 (2008) 12242-12243.

[27] N.A. Birkin, O.J. Wildig, S.M. Howdle, Effects of poly(vinyl pivalate)-based stabiliser architecture on $\mathrm{CO}_{2}$-solubility and stabilising ability in dispersion polymerisation of $\mathrm{N}$-vinyl pyrrolidone, Polym. Chem. 4 (2013) 3791.

[28] E. Girard, T. Tassaing, C. Ladavière, J.-D. Marty, M. Destarac, Distinctive Features of Solubility of RAFT/MADIX-Derived Partially Trifluoromethylated Poly(vinyl acetate) in Supercritical $\mathrm{CO}_{2}$, Macromolecules 45 (2012) 9674-9681.

[29] B. Tan, C.L. Bray, A.I. Cooper, Fractionation of Poly(vinyl acetate) and the Phase Behavior of End-Group Modified Oligo(vinyl acetate)s in $\mathrm{CO}_{2}$, Macromolecules 42 (2009) 7945-7952.

[30] A. Mohamed, K. Trickett, S.Y. Chin, S. Cummings, M. Sagisaka, L. Hudson, S. Nave, R. Dyer, S.E. Rogers, R.K. Heenan, J. Eastoe, Universal Surfactant for Water, Oils, and $\mathrm{CO}_{2}$, Langmuir 26 (2010) 13861-13866.

[31] M.T. Stone, S.R. da Rocha, P.J. Rossky, K.P. Johnston, Molecular differences between hydrocarbon and fluorocarbon surfactants at the $\mathrm{CO}_{2}$ /water interface, J. Phys. Chem. B 107 (2003) 10185-10192.

[32] M.T. Stone, P.G. Smith, S.R. da Rocha, P.J. Rossky, K.P. Johnston, Low interfacial free volume of stubby surfactants stabilizes water-in-carbon dioxide microemulsions, J. Phys. Chem. B 108 (2004) 1962-1966.

[33] S. Zhang, K. Chen, L. Liang, B. Tan, Synthesis of oligomer vinyl acetate with different topologies by RAFT/MADIX method and their phase behaviour in supercritical carbon dioxide, Polymer 54 (2013) 5303-5309.

[34] N.A. Birkin, N.J. Arrowsmith, E.J. Park, A.P. Richez, S.M. Howdle, Synthesis and application of new $\mathrm{CO}_{2}$-soluble vinyl pivalate hydrocarbon stabilisers via RAFT polymerisation, Polym. Chem. 2 (2011) 1293-1299.

[35] J. Gregorowicz, Z. Fraś, P. Parzuchowski, G. Rokicki, M. Kusznerczuk, S. Dziewulski, Phase behaviour of hyperbranched polyesters and polyethers with modified terminal $\mathrm{OH}$ groups in supercritical solvents, J. Supercrit. Fluids 55 (2010) 786-796.

[36] R.F. Fedors, A method for estimating both the solubility parameters and molar volumes of liquids, 
Polym. Eng. Sci. 14 (1974) 147-154.

[37] H. Sun, COMPASS: an ab initio force-field optimized for condensed-phase applications overview with details on alkane and benzene compounds, J. Phys. Chem. B 102 (1998) 7338-7364.

[38] D. Rigby, H. Sun, B.E. Eichinger, Computer simulations of poly(ethylene oxide): force field, pvt diagram and cyclization behaviour, Polym. Int. 44 (1997) 311-330.

[39] J. Yang, Y. Ren, A.-m. Tian, H. Sun, COMPASS Force Field for 14 Inorganic Molecules, He, Ne, Ar, $\mathrm{Kr}, \mathrm{Xe}, \mathrm{H}_{2}, \mathrm{O}_{2}, \mathrm{~N}_{2}, \mathrm{NO}, \mathrm{CO}, \mathrm{CO}_{2}, \mathrm{NO}_{2}, \mathrm{CS}_{2}$, and $\mathrm{SO}_{2}$, in Liquid Phases, J. Phys. Chem. B 104 (2000) 4951-4957.

[40] H. Sun, D. Rigby, Polysiloxanes: ab initio force field and structural, conformational and thermophysical properties, Spectrochim. Acta, Part A 53 (1997) 1301-1323.

[41] B.E. Eichinger, D. Rigby, J. Stein, Cohesive properties of Ultem and related molecules from simulations, Polymer, 43 (2002) 599-607.

[42] D. Rigby, Fluid density predictions using the COMPASS force field, Fluid Phase Equilib. 217 (2004) 77-87.

[43] D. Hu, S. Sun, P.Q. Yuan, L. Zhao, T. Liu, Exploration of $\mathrm{CO}_{2}$-Philicity of Poly(vinyl acetate-co-alkyl vinyl ether) through Molecular Modeling and Dissolution Behavior Measurement, J. Phys. Chem. B 119 (2015) 12490-12501.

[44] J. Bernard, A. Favier, L. Zhang, A. Nilasaroya, T.P. Davis, C. Barner-Kowollik, M.H. Stenzel, Poly(vinyl ester) star polymers via xanthate-mediated living radical polymerization: from poly(vinyl alcohol) to glycopolymer stars, Macromolecules 38 (2005) 5475-5484.

[45] A. Gregory, M.H. Stenzel, Complex polymer architectures via RAFT polymerization: From fundamental process to extending the scope using click chemistry and nature's building blocks, Prog. Polym. Sci. 37 (2012) 38-105.

[46] N.A. Birkin, N.J. Arrowsmith, E.J. Park, A.P. Richez, S.M. Howdle, Synthesis and application of new $\mathrm{CO}_{2}$-soluble vinyl pivalate hydrocarbon stabilisers via RAFT polymerisation, Polym. Chem. 2 (2011) 1293-1299.

[47] Y.Y. Tong, R. Wang, N. Xu, F.S. Du, Z.C. Li, Synthesis of well-defined azide-terminated poly(vinyl alcohol) and their subsequent modification via click chemistry, J. Polym. Sci., Part A: Polym. Chem. 47 (2009) 4494-4504.

[48] Y. Fu, L. Liao, L. Yang, Y. Lan, L. Mei, Y. Liu, S. Hu, Molecular dynamics and dissipative particle dynamics simulations for prediction of miscibility in polyethylene terephthalate/polylactide blends, Mol. Simulat. 39 (2013) 415-422.

[49] C. Pouteau, S. Baumberger, B. Cathala, P. Dole, Lignin-polymer blends: evaluation of compatibility by image analysis, CR Biol. 327 (2004) 935-943.

[50] D. Li, A. Neumann, Contact angles on hydrophobic solid surfaces and their interpretation, J. Colloid Interface Sci. 148 (1992) 190-200.

[51] T.C. Clancy, W.L. Mattice, Miscibility of Poly(vinyl chloride) Melts Composed of Mixtures of Chains with Differing Stereochemical Composition and Stereochemical Sequence, Macromolecules 34 (2001) 6482-6486. 


\section{Captions}

Scheme 1. Synthesis of 3-armed and 4-armed R-core Star Xanthate Agents.

Figure 1. ${ }^{1} \mathrm{HNMR}$ spectra of (a) 4-armed R-core Star Xanthate agent and corresponding (b) 4-armed R-core star PVAc and (c) the end-removed product.

Figure 2. Evolution of the mocular weight and molecular weight distribution with conversion for polymerization with two 3 -armed and 4 -armed RAFT agents of VAc at $60{ }^{\circ} \mathrm{C}$. The lines only indicate the trend.

Figure 3. Gel permeation chromatograms for two samples of (a) 3-armed PVAc and (b) 4-armed PVAc and the products obtained by their reduction with dillauroylperoxide in 2-propanol $\left(80^{\circ} \mathrm{C} / 6 \mathrm{~h}\right)$. Peak molecular weights are exhibited on the chromatograms.

Figure 4. Effect of the molecular weight on the cloud point pressures of (a) PVAc with different molecular structure and (b) the products obtained by their reduction of end groups. The lines only indicated the trend. ( $\triangle$ and $\triangle$ were measured at $30{ }^{\circ} \mathrm{C}$ with a polymer amount of $0.1 \mathrm{~g}$ in a $10 \mathrm{~mL}$ cell, and other data points were all measured at $35{ }^{\circ} \mathrm{C}$ with a concentration of $0.2 \mathrm{wt} \% \mathrm{CO}_{2}$ ).

Figure 5. Effect of $M_{\mathrm{n}}$ on simulated CED and solubility parameter of PVAc with different structures.

Figure 6. The surface tension of PVAc with different molecular structure and molecular weight.

Figure 7. Flory-Huggins interaction parameter between $\mathrm{CO}_{2}$ and $\mathrm{PVAc}$ with different $M_{\mathrm{n}}$ and different structures

Figure 8. Intermolecular distribution for the C-C pairs in PVAc with different $M_{\mathrm{n}}$ and different structures.(a) $2580 \mathrm{~g} / \mathrm{mol}$; (b) $4300 \mathrm{~g} / \mathrm{mol}$; (c) $6450 \mathrm{~g} / \mathrm{mol}$.

Figure 9. Intermolecular distribution for the $\mathrm{C}-\mathrm{C}$ pairs between polymer chains and $\mathrm{CO}_{2}$. (a) $2580 \mathrm{~g} / \mathrm{mol}$; (b) $4300 \mathrm{~g} / \mathrm{mol}$; (c) $6450 \mathrm{~g} / \mathrm{mol}$.

Table 1. Systems with different compositions of $\mathrm{PVAc}$ and $\mathrm{CO}_{2}$ in $\mathrm{MD}$ simulations

Table 2. Experiment result for the synthesis of linear and multi-armed PVAc

Table 3. Interaction energy between a single polymer chain and $1000 \mathrm{CO}_{2}$ molecules. $(\mathbf{k J} / \mathbf{m o l})$ 


\section{Graphic Abstract}

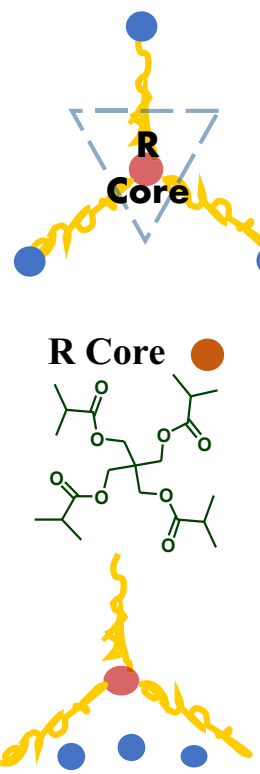

3-armed PVAc
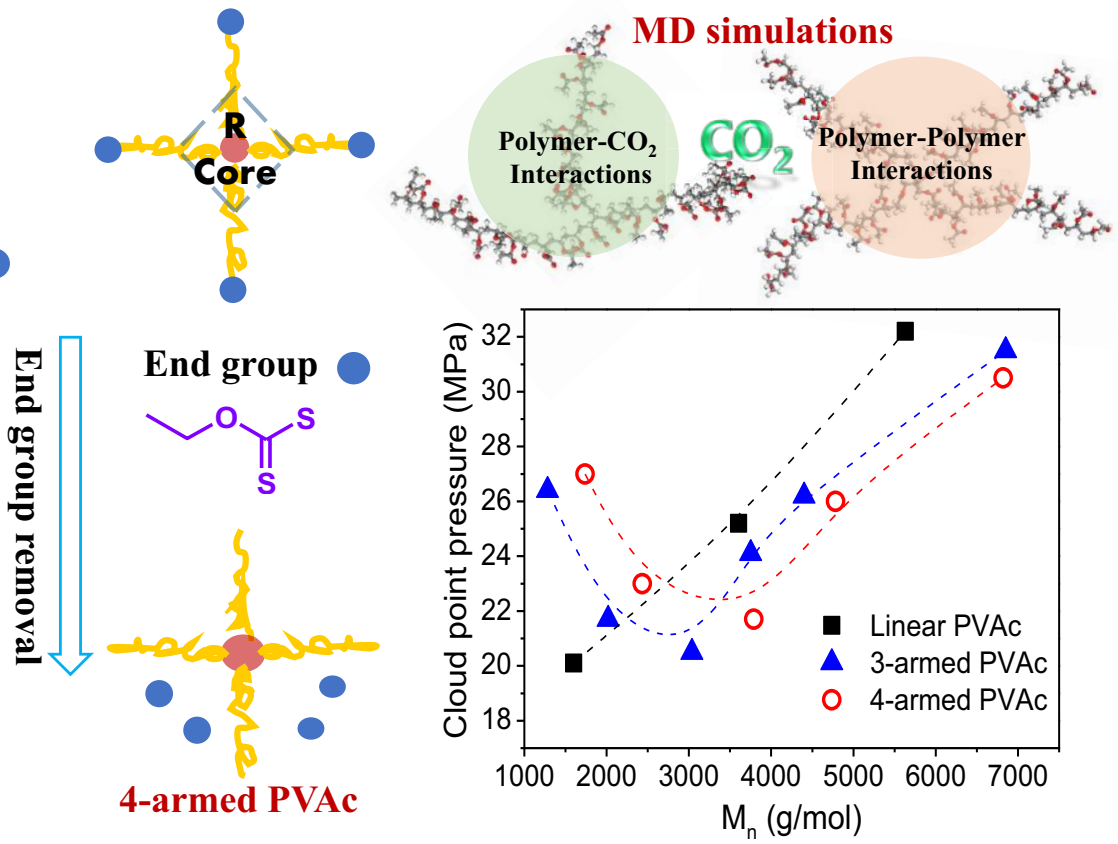